\title{
LOS MENSAJES NAVIDEÑOS DE LA MONARQUÍA ESPAÑOLA EN EL SIGLO XXI: ¿UN REFLEJO DE LOS PRINCIPALES PROBLEMAS DEL PAÍS? ${ }^{1}$
}

\author{
THE CHRISTMAS MESSAGES FROM THE SPANISH MONAR- \\ CHY IN THE 21ST CENTURY: A REFLECTION OF THE MAIN IS- \\ SUES OF THE COUNTRY?
}

\author{
Agustín García-Ramos \\ Universidad de Alicante (Spain) \\ agus.garciaramos@ua.es
}

\section{Resumen}

A pesar de la indudable trascendencia de los mensajes que el rey de España dirige a la población cada Nochebuena, la sociología apenas ha abordado su estudio sistemático. El presente artículo pretende paliar en parte esa carencia, explorando la manera en que dichos mensajes reflejan los principales problemas de España, recogidos regularmente por el Centro de Investigaciones Sociológicas en sus barómetros. A tal fin, se recurre a la técnica del análisis de contenido, de marcado carácter cuantitativo. Los resultados revelan que las referencias a los problemas de España ocupan algo menos de la mitad de la extensión total de los mensajes, y que el dimensionamiento de los distintos problemas es bastante desigual. Esta desigualdad parece obedecer a una estrategia monárquica de legitimación institucional y mantenimiento del statu quo.

\section{Palabras clave}

Mensajes de Navidad, monarquía española, problemas de España, discurso institucional, estrategias de comunicación, análisis de contenido

\footnotetext{
${ }^{1}$ El presente artículo es una reelaboración del Trabajo Fin de Grado presentado por el autor, bajo la tutela del profesor Clemente Penalva Verdú, con vistas a la obtención del Grado en Sociología por la Universidad de Alicante.
} 


\begin{abstract}
Despite the undeniable importance of the speeches that the King of Spain addresses to the citizenry every Christmas Eve, sociologists have barely dealt with its study in a systematic way. This paper aims to remedy this lack, exploring how these speeches reflect the main public concerns of Spain, regularly collected by the Center for Sociological Research in their barometers. To this end, a highly quantitative analysis content technique has been applied. The survey results reveal that references to the concerns occupy slightly less than half of the total length of the speeches, and the ratio of the various issues is quite uneven. This observed imbalance seems to respond to a monarchical strategy of institutional legitimation and maintenance of the status quo.
\end{abstract}

\title{
Keywords
}

Christmas speech, Spanish monarchy, main issues in Spain, institutional discourse, communication strategies, content analysis

\section{Extended abstract}

Since the restoration of the monarchy in Spain, in 1975, it has become customary for the king to give a nationally televised Christmas Eve speech. This speech, which is called Christmas message, is the main instrument of communication of the head of the State with citizens, that's why it is very popular and gains a huge media attention. However, despite its importance, there are virtually no studies on the Christmas messages that make use of a wide diachronic perspective, and the few that exist come from fields such as journalism, law, discourse analysis or semiotics, but not sociology.

This article aims partly to alleviate some of that shortage. Furthermore, this is achieved using an unusual approach: the linking of such messages with surveys about the main issues in Spain, collected by the Center for Sociological Research (known by its Spanish acronym, CIS) in their monthly barometers. Since these barometers represent the most reliable way to get to know the state of public opinion, and Christmas messages are the king's most personal and free public words, the ultimate goal of this study is simply to confront these two approaches - public opinion versus monarchy - on the same subject: the main issues of the country.

To implement this goal, we resort to the markedly quantitative content analysis technique. The methodological modus operandi, before analyzing the data, consists of two phases. First of all, the main issues in Spain are inserted as codes in the Atlas.ti software, thus implementing the precoding process characteristic of this technique. Secondly, Christmas messages from the studied period 20012015 inclusive, have been introduced in this software, thereby forming primary documents. Once the Hermeneutic Unit has been configured, begins, with es- 
Los mensajes navideños de la monarquía Española en el siglo XXI:

¿Un reflejo de los principales problemas del país?

sentially exploratory purposes, the study on the degree in which the main issues of Spain are present in the Christmas messages and how such presence is modulated. To this end, the paragraph has been chosen as the unit of analysis, and an ad hoc unit of measure has been created: the allusion, used precisely to point out the conflicting references to the main issues of the country in the Christmas messages.

When approaching the study of the Christmas messages some theoretical considerations, divided into 4 sections, have been taken into account: 1) the historicity of Christmas messages; 2) the classifications that are subject to the royal speeches in general, the highly political and institutional character of Christmas messages in particular, and the purpose of the latter, which can be synthesized in a constant search for legitimacy of the monarchy and maintenance of its status quo; 3 ) the various communication strategies being employed by the king in the Christmas messages to achieve his goals, such as framing, priming, the deliberate lack of specificity or the use of ambiguity; and 4), the topics addressed, which, together with a number of consistent themes, are appearing and disappearing according to the context, simultaneously to a theoretical increase in sensitivity of the king's words.

The degree of presence of the main issues of Spain in the Christmas messages is the first of the issues discussed in the research. In this regard, the study gives an average of 29 allusions to these issues in every Christmas message, with a range that goes from 9 allusions in 2001 to 47 in 2008. Since not all messages have the same length and the same number of paragraphs, the relative presence of the main issues of Spain in Christmas messages has been examined, resulting in mean figures of 0.85 allusions by paragraph, with a minimum of 0.5 in 2001 and a maximum of 1.36 in 2010, and 20.98 per 1000 words allusions, with a minimum of 9.35 in 2001 and a maximum of 31.45 in 2010. Finally, but perhaps most importantly, the distribution of these allusions in the Christmas messages is studied, resulting in $51.66 \%$ of paragraphs that contain no reference whatsoever, $28.89 \%$ containing $1,11.22 \%$ containing $2,3.66 \%$ containing $3,1.24 \%$ containing 4 and $3.32 \%$ containing 5 or more.

Hereafter, differences in the way that the main issues of Spain are reflected in the CIS barometers and the Christmas messages are addressed. In that sense, the analyses reveal many similarities in the emphasis placed on the most important issues in both variables. However, it also becomes clear that there are problems over and undersized in the Christmas messages in relation to the CIS barometers. The oversized problems generally include those which are able to generate greater consensus, while undersized correspond to those likely to alienate viewers against the monarch, leading to some kind of discomfort or disagreement.

Thereupon, when comparing the evolution of the 5 main issues in Spain in the CIS barometers, on the one hand, and in the Christmas messages on the other, a 
longitudinal perspective is adopted. The comparison shows a statistically significant direct correlation among all these issues, except "Immigration" which is hardly regarded as a controversial in the Christmas messages. Such a correlation can be classified as very high in the case of "The problems of an economic nature" and as high for "ETA terrorism" and " Unemployment ".

Finally, the recurrence rate of each issue, understood as the percentage of Christmas messages where there is at least one reference to a given issue is determined. The data obtained suggest that 3 of the 5 issues with a higher percentage of recurrence are also among the 5 most oversized: "The social problems", "The problems of an economic nature" and "Personal concerns and situations".

In the concluding chapter, it can be said that the main issues in Spain have an average presence in the Christmas messages. The review also shows that the period between 2008 and 2014 contains the biggest amount of allusions. Hence it can be described as the one where the monarch gets closer to the main problems of the country. This endorses partially the existing hypotheses reflected in previous studies on this subject.

Moreover, it is undeniable the relative correspondence between the consideration of the most important issues of Spain both in barometers and in the Christmas messages. However, unequal treatment of other minor problems occurs in parallel, reflected both on the over and under-sizing of some of them and their different degrees of recurrence. This seems to confirm the idea, also manifest in the previous literature, that the monarchy uses certain communication strategies to project a friendly image of the situation in Spain, an image that does not always correspond with the concerns of the population. By doing this, thus, the king seeks to convince the audience of the benefits of the status quo, thereby contributing to its maintenance and hence the legitimacy and perpetuation of the monarchic institution.

\section{INTRODUCCIÓN}

Desde la reinstauración de la monarquía en España en 1975, y siguiendo una tradición implantada a nivel nacional por Francisco Franco durante la dictadura (García Pujol, 2016; Palacio, 2002), ha devenido en costumbre que el titular de la Corona dirija un mensaje televisado a la población la noche del 24 de diciembre. Dicho mensaje es difundido simultáneamente por la mayoría de las cadenas y emisoras de radio - y desde 2010 (García Fernández, 2015), también a través de Internet-, lo que lo convierte año tras año en una de los programas más vistos y escuchados (Barlovento Comunicación, 2015a, 2015b) en todo el territorio. Puede afirmarse, pues (Cruz, 2015), que los mensajes de Navidad del rey de España (en adelante, mensajes de Navidad, mensajes navideños o, simplemente, mensajes) constituyen el principal instrumento en la relación del monarca con la 
Los mensajes navideños de la monarquía Española en el siglo XXI:

¿Un reflejo de los principales problemas del país?

ciudadanía, lo que los convierte en el acto comunicativo más trascendente de la institución más alta del Estado, según la Constitución Española (Medina López, 2016; Ruiz Ruiz, 2001). De ahí que los mensajes navideños se hayan erigido, sin lugar a dudas, "en un referente de primerísima mano para conocer la práctica totalidad de la política española en estos años, tanto la nacional como la internacional, así como los distintos avatares y variadas preocupaciones de los españoles" (González-Trevijano, en el prólogo de Medina López, 2016).

Como no podría ser de otra manera, las palabras del monarca son analizadas de forma pormenorizada por los diversos medios de comunicación, alcanzando su contenido y forma una resonancia sobresaliente (Barredo Ibáñez, 2013; Martín Jiménez, 2008, 2010; Medina López, 2016; Ventero Velasco, 2010). En tales análisis, no son infrecuentes las comparaciones entre años correlativos; sin embargo, apenas existen estudios sobre el contenido textual de este tipo de alocuciones regias que tengan en cuenta una perspectiva diacrónica amplia. Entre esas escasas excepciones ocupa un lugar destacado, por derecho propio, la monografía sobre el tema de Ventero Velasco (2010). Junto a ella, cabe destacar los trabajos de Martín Jiménez $(2008,2010)$ y Barredo Ibáñez (2013), desarrollados desde una óptica eminentemente periodística - en el caso de este último, haciendo uso, además, de la Teoría Fundamentada o Grounded Theory-, los de Gonzalo (2001) y Ruiz Ruiz (2001), desde el ámbito del derecho constitucional, o un reciente artículo de Medina López (2016), desde los presupuestos del análisis del discurso y la semiótica de la comunicación. En otros países, este tipo de investigaciones de largo alcance posee una mayor raigambre. De entre ellas, vale la pena citar, siquiera por la amplitud del periodo analizado, la realizada por Kredátusová (2009), mediante la técnica del análisis de discurso, sobre los mensajes navideños de la reina Isabel II de Inglaterra entre 1952 y 2007.

El presente texto pretende paliar, en una pequeña parte, la referida ausencia de análisis longitudinales sobre el contenido textual de los mensajes navideños en el campo de la sociología. Y lo hace, además, valiéndose de un enfoque inédito: la puesta en relación de dichos mensajes con la interpelación sobre la "Percepción de los principales problemas de España", recogida en los barómetros realizados mensualmente por el Centro de Investigaciones Sociológicas (CIS, en adelante). En la medida en que los barómetros sirven para "medir el estado de la opinión pública española del momento" (CIS, s. f., s. p.) y los mensajes navideños constituyen las palabras públicas más personales y libres del rey (Gonzalo, 2001; Medina López, 2016; Ventero Velasco, 2010), el objetivo principal del estudio radica en averiguar si la monarquía es, en este tipo de comparecencias, sensible a la opinión pública y a las vicisitudes de la ciudadanía, manifiestas en la pregunta sobre los principales problemas del país contenida en los barómetros. Así pues, la valoración y clasificación de los principales problemas de España proporcionada por el CIS constituiría la variable independiente, mientras que los mensajes navideños - o más bien las alusiones a los principales pro- 
blemas de España contenidas en ellos - integrarían la variable dependiente, aunque la posibilidad de correlación entre ambas no implica stricto sensu una relación de causalidad.

Para implementar este enfoque, se recurre a una perspectiva cuantitativa, que, aplicada a los mensajes navideños, rara vez se ha aventurado más allá de la mera contabilización de palabras. Quizá la única salvedad en este sentido la constituyan la referida monografía de Ventero Velasco (2010) y el estudio de Ortega, Concejero y de Uña (2014), quienes, valiéndose del software estadístico $\mathrm{R}$, han aplicado una adaptación al español del coeficiente de perspicuidad de Flesch-Kincaid y los llamados n-gramas. Ciertamente, existe un precedente, muy reciente, de aplicación diacrónica de la perspectiva cuantitativa a las disertaciones del rey en un artículo de Ballenilla y García de Gamarra (2015). Sin embargo, este se focaliza en los discursos pronunciados con motivo de la Pascua Militar, no en los mensajes navideños.

La técnica empleada para desarrollar el estudio ha sido la del análisis de contenido. Como es sabido, dicha técnica se basa en el recurso a la precodificación, al objeto de lograr la "descripción objetiva $-\mathrm{y}$ cuantitativa - del contenido manifiesto" (Penalva Verdú, Alaminos Chica, Francés García, y Santacreu Fernández, 2015, p. 100). A partir de ese proceso, y mediante el empleo de los programas de análisis cualitativo de datos y análisis estadístico Atlas.ti y SPSS, se ha pretendido determinar, con fines fundamentalmente exploratorios, el grado de presencia de los principales problemas de España en los mensajes navideños, así como la forma en que se modula dicha presencia. A tal fin, se ha creado una unidad de medida ad hoc: la alusión, consagrada, precisamente, a señalar las referencias conflictuales a los principales problemas del país en los mensajes navideños.

Otra de las características centrales del análisis de contenido radica (Krippendorff, 1990) en su sensibilidad al contexto, "en el sentido de que las inferencias y la interpretación se han de vincular con las condiciones de producción del texto" (Mateo Pérez, Penalva Verdú y La Parra-Casado, 2004, p. 220). Precisamente, la vinculación de los mensajes navideños con las condiciones en que han sido alumbrados, así como la multitud de elementos implícitos y sobrentendidos en ellos, han sido puestas de relieve por Ventero Velasco (2010) primero, y Medina López (2016) más tarde. Sin embargo, y máxime teniendo en cuenta las dimensiones forzosamente reducidas de este estudio, resulta imposible atender a todos y cada uno de los determinantes y referencias socio-históricas del material analizado. De ahí que se haya optado por poner el foco solo en algunos de esos determinantes y referencias. Entre los mismos figuran los antecedentes de los mensajes navideños, su finalidad, el recurso en ellos a diversas estrategias comunicativas y su temática, amén de unas breves notas sobre las clasificaciones de las alocuciones regias y las características del discurso político e institucional. 
Los mensajes navideños de la monarquía Española en el siglo XXI:

¿Un reflejo de los principales problemas del país?

\section{MARCO TEÓRICO}

\subsection{Antecedentes de los mensajes navideños}

La costumbre de dirigir un mensaje a la población por parte de un mandatario en fechas cercanas a la Navidad existía mucho antes del ascenso a la jefatura del Estado del hoy exrey Juan Carlos I (Barredo, 2013; García Pujol, 2016; Medina López, 2016). Diversos autores (Barredo, 2013; Martínez-Fornés, 2014; García Pujol, 2016) atribuyen la paternidad de la idea a John Reith, el ejecutivo que estableció la tradición de independencia del servicio público de radiodifusión en el Reino Unido. Habría sido este quien, en 1932, propuso al monarca Jorge V la inauguración del servicio mundial de la $\mathrm{BBC}$ con un mensaje retransmitido por radio a todo el Imperio británico. El éxito de la iniciativa, que llegó a una audiencia récord en la época de cerca de 20 millones de personas, provocó (Martínez-Fornés, 2014) que otros dirigentes adoptaran lo que hoy es una costumbre fuertemente arraigada no solo en la mayoría de las monarquías democráticas del mundo, sino también en muchos sistemas republicanos (Medina López, 2016). De esta manera, ya en 1933, el entonces presidente estadounidense Franklin D. Roosevelt transmitía su primer discurso navideño a todo el país. En España, Francisco Franco hacía lo propio en 1937, en plena Guerra Civil (García Pujol, 2016). Tras su victoria en la contienda, el a la sazón proclamado Generalísimo adquirió la costumbre, que mantuvo hasta 1974, de dirigirse a la nación durante las fiestas navideñas. Tales alocuciones fueron, como cabría esperar, primero radiadas y, ya en la segunda mitad del siglo XX (Palacio, 2002), también televisadas.

Las comparecencias de Franco se concibieron (Palacio, 2002), además de como felicitación al pueblo con motivo de las fiestas, como un resumen de los principales acontecimientos acaecidos a lo largo del año. Seguramente por ese carácter de recapitulación, las mismas fueron mayoritariamente emitidas la noche del 31 de diciembre, lo que les valió la denominación oficial de Mensaje de fin de año. Tras la muerte del dictador, el por entonces recién nombrado rey Juan Carlos I prolongó la costumbre de dirigirse al pueblo en las fiestas navideñas, si bien, al objeto de desmarcarse de su antecesor (García Pujol, 2016), trasladó su alocución a la Nochebuena. Desde entonces, las grabaciones se han emitido, sin excepción, en esa fecha, razón por la cual su denominación oficial ha pasado a ser la de Mensaje de Navidad de Su Majestad el Rey.

\subsection{Clasificaciones de las alocuciones regias}

Las palabras vertidas públicamente por el rey han sido objeto de diversas clasificaciones en función de los distintos criterios utilizados por sus estudiosos. Así, Gonzalo (2001) distingue, según la índole de las mismas, entre mensajes y 
discursos. Los primeros poseen "un hondo significado constitucional de compromiso para la acción política de futuro", (Gonzalo, 2001, p. 89) y serían relativamente escasos. Entre ellos, evidentemente, ocupa un lugar descollante un tipo concreto de "alocuciones orales escenificadas" (Barredo, 2013, p. 124) y ritualizadas, como son los mensajes de Navidad:

...reciben el nombre de mensajes de Navidad, aun cuando están primados de significado político directo, los discursos televisados destinados a mantener un vínculo periódico con los ciudadanos al rememorar los acontecimientos del año y propiciar vías de solución futura a los problemas pendientes, entre los cuales el terrorismo y el paro ocupan el lugar más destacado y permanente (Gonzalo, 2001, p. 90).

En cuanto a los discursos, cuyo número sería mucho mayor, hacen referencia a una panoplia de temas, por lo que (Ruiz Ruiz, 2001) no todos ellos pueden etiquetarse como políticos ni presentan la misma relevancia institucional. A propósito de la distinción entre mensajes y discursos, Llorca (1985, en Medina López, 2016, p. 31) advierte que "durante el reinado de Juan Carlos I se cambia radicalmente el sentido de los discursos, de tal manera que se prefiere el termino mensaje", al objeto de desvincularse de toda responsabilidad gubernativa, incidiendo, de paso, en la imbricación de la Corona en el engranaje constitucional.

Quizá siguiendo esa línea, Ventero Velasco (2010) se refiere en casi todo momento a las palabras públicas del rey como mensajes, y distingue 3 tipos de estos en función de su frecuencia y auditorio: los de carácter anual - entre los cuales figurarían los mensajes navideños -, los pronunciados antes las Cortes Generales y, finalmente, los de carácter ocasional. En otro punto de su exhaustivo tratado, el propio Ventero Velasco (2010) se hace eco de la distinción de Herrero Rodríguez de Miñón (1984) entre mensajes de cortesía y propiamente políticos, englobando entre estos últimos los mensajes navideños. El carácter inconcusamente político de los mensajes navideños ha sido enfatizado también por autores como Gonzalo (2001), Ventero Velasco (2010), Gaspar e Ibeas (2015) o Medina López (2016).

\subsection{Discurso político e institucional y finalidad de los mensajes navideños}

En relación al carácter político de los mensajes navideños, vale la pena traer a colación la aportación de Gutiérrez (1999), quien, en su revisión de la bibliografía existente sobre el discurso político, espiga 2 tipos de concepciones sobre este: una restrictiva, en la que el discurso es producido exclusivamente desde ámbitos institucionales y de poder, y otra extensiva, en la que lo político es entendido en un sentido más amplio, sobre todo atendiendo a aspectos puramente ideológicos o intencionales. De manera evidente, los mensajes navideños pue- 
Los mensajes navideños de la monarquía Española en el siglo XXI:

¿Un reflejo de los principales problemas del país?

den inscribirse en el primer grupo, pues se trata sin duda de discursos institucionales (Medina López, 2016). Entre los rasgos distintivos de este último tipo de discursos, Prego Vázquez (1998) destaca la asimetría de las relaciones, la negociación de poder, el uso de mecanismos discursivos específicos, la ausencia de turnos, la elección del léxico, la forma indirecta de introducir tópicos o la negociación de significados sociales y culturales mediante las fuentes lingüísticas.

A nivel teórico, el solapamiento constante entre el discurso político y el institucional tiene su principal manifestación en una evidente finalidad persuasiva. Los mensajes navideños, en tanto que claras manifestaciones de uno y otro tipo de discurso, no son ajenos a dicha finalidad (Gaspar e Ibeas, 2015; Herrero Rodríguez de Miñón, 1984; Medina López, 2016; Ruiz Ruiz, 2001; Ventero Velasco, 2010). Parece lógico, pues, que esta clase de alocuciones regias observe, según dichos autores, un marcado tono exhortativo o ilocutivo, con el que, más que informar, se pretende influir en el público de cara a la creación o el mantenimiento de un imaginario concreto (Kellner, s. f., en Ardanaz, 2000). De esta manera, el discurso político y el institucional acaban convirtiéndose en correa de transmisión de la ideología dominante (Van Dijk, 2009), "un requisito imprescindible para la hegemonía política e ideológica de los poderes y de los estados" (Burton y Carlen, 1979, en Medina López, 2016; p. 26).

Cabe, a propósito de lo anterior, preguntarse por la intención ulterior de las disertaciones del monarca en Nochebuena. Dicho de otra manera: con sus palabras, el rey busca convencer a la nación, pero ¿convencer de qué? ¿Cuál es, valga la redundancia, el mensaje de los mensajes navideños? Para Ruiz Ruiz (2001, p. 531), "la función de los discursos y mensajes regios ha de ser la de una pedagogía constitucional". Según Ventero Velasco (2010), los mensajes navideños son utilizados por el jefe del Estado para el desempeño de su función de arbitrio y moderación, así como para la transmisión más o menos explícita de elementos de naturaleza política. Medina López (2016) hace hincapié en los continuos intentos de afianzamiento de la Corona, la reivindicación de los valores democráticos y constitucionales, además de en los llamamientos a la unidad de España y sus habitantes. Gaspar e Ibeas (2015), a pesar de que su análisis se circunscribe únicamente al mensaje de Navidad del año 2012, destacan que el objetivo fundamental de este no fue otro que restaurar la credibilidad perdida por el rey a raíz de los escándalos que le salpicaron desde finales de 2011, amén de consolidar el statu quo socio-político. Abundando en esa cuestión, Medina López (2016) razona que, si bien la necesidad de legitimación se fue diluyendo con el pleno asentamiento de la democracia, el descenso de la popularidad de la monarquía a partir de 2011 obligó a colocar el asunto de nuevo en primer plano. La constante búsqueda de legitimación de la Corona ante la sociedad, independientemente de las circunstancias, ha sido también puesta de relieve, aunque desde una óptica más combativa, por Zugasti (2005), Ramos (2012), Ramos Fernández 
(2013) y Barredo Ibáñez (2013). En esa línea, Rodríguez García (2007) denuncia el afán por construir un imaginario monárquico que pretende hacer ver la institución como algo natural y, por tanto, no sujeto a discusión. Sea como fuere, bien desde una óptica más moderada, bien más beligerante, todos los autores citados parecen coincidir en que los mensajes navideños dejan traslucir una impronta más bien conservadora, en la que prima lo políticamente correcto y la búsqueda del consenso, con el objeto, a la postre, de mantener la estructura organizativa del Estado y el orden establecido.

\subsection{Estrategias comunicativas en los mensajes navideños}

Desde la última década del siglo XX (Sádaba Garraza, Rodriguez Virgili y Bartolomé Castro, 2012), han proliferado las aproximaciones a los discursos políticos que se valen de la teoría del encuadre o framing. Este concepto "preside de hecho toda la generación discursiva (...) es la base cognitiva sobre la que se asienta toda comunicación efectiva $\mathrm{y},(\ldots)$ supone un fondo informativo compartido por emisión y recepción" (Gallardo Paúls, 2014, p. 24). Es precisamente esa omnipresencia la que dota al framing de una enorme versatilidad a la hora de ser aplicado. Así, Sádaba Garraza et al. (2012) destacan su doble vertiente, psicológica y sociológica, su carácter representativo y simbólico, así como su posible aplicación tanto a las figuras del emisor y el receptor como al propio contenido del mensaje o al contexto cultural en que este ha sido producido. Esa aparente ubicuidad teórica no debe desmerecer en absoluto la importancia del concepto, pues, como recalca Humanes (2003, p. 42), "la manera como se enfoca un tema (variable independiente) influye en la percepción que el público desarrolla sobre ese asunto (variable dependiente)". Además, conviene recordar que la utilización de un framing determinado está, en el caso de los discursos políticos e institucionales, al servicio de un objetivo clave, como es la persuasión: “...si un emisor consigue instaurar su propio marco en el mensaje, si logra que el destinatario interprete las cosas a la luz sugerida por su actividad de encuadre, tiene adelantado el paso básico de la persuasión" (Gallardo Paúls, 2014, p. 24).

Inequívocamente, el rey, en todos sus discursos en general, y en los mensajes navideños en particular, hace uso de la estrategia del framing. Tal estrategia consiste, en este caso concreto, en la búsqueda de puntos de acuerdo entre el emisor y la audiencia:

Y este planteamiento del locutor para introducir al auditorio en el marco mental adecuado para sus intereses se articula esencialmente mediante un tipo de valores que son compartidos por la mayoría del auditorio, como el bien común, la lealtad, el respeto mutuo, la ayuda a los desfavorecidos, el bienestar o los derechos sociales, valores que jalonan el texto navideño (Lakoff, 2004). En efecto, la utilización de valores generales es uno de los recursos argumentativos reco- 
mendados por la retórica clásica y se ha convertido en una característica cada vez más general de los discursos políticos contemporáneos. Se trata de generar adhesión utilizando valores que no es posible contradecir sin desmontar el sistema. ¿Quién negaría la bondad del bien común, clamaría contra la defensa de la lucha contra la corrupción o argumentaría contra la protección de los más desfavorecidos? (Gaspar e Ibeas, 2015, p. 35).

De esta forma, los mensajes navideños anteponen de manera clara unos temas a otros (Gaspar e Ibeas, 2015; Medina López, 2016; Ventero Velasco, 2010), lo que redunda en el uso añadido de la estrategia comunicativa conocida como priorización o priming, consistente, precisamente, en otorgar relevancia a determinados aspectos de la actualidad política, en detrimento de otros (Gallardo Paúls, 2014).

Junto al framing y el priming, es posible encontrar otras estrategias comunicativas en los mensajes navideños. Ventero Velasco (2016, p. 421) resalta entre ellas una cierta ambigüedad premeditada, así como el recurso a "contenidos latentes", que se dirigen a colectivos específicos, y no al auditorio en general, valiéndose del "diferencial informativo" entre unos y otro. A su vez, Gaspar e Ibeas (2015) hacen hincapié en el tono calculadamente impreciso de las palabras del rey, utilizado para no profundizar en muchos asuntos o evitar tomar partido.

\subsection{Temática de los mensajes navideños}

Siendo los discursos regios un terreno sujeto al constante escrutinio público, no resulta extraño que los asuntos abordados en ellos hayan sido pasto de exhaustivos análisis, si bien son escasos los que aplican una perspectiva longitudinal. En este terreno descuella, una vez más, el estudio realizado por Ventero Velasco (2010), que abarca los mensajes navideños pronunciados entre $1975 \mathrm{y}$ 2009. Dicho estudio subraya, en primer lugar, la existencia de un número de temas no superior a 20, la mayoría correspondientes a cuestiones de Estado, a los que el monarca alude de forma constante. Entre tales temas, los 5 con una mayor presencia en la serie histórica son: "Unidad de los españoles y de la Patria" (33 apariciones sobre 35 mensajes analizados, esto es, un $94 \%$ de presencias), "Monarquía" (31 apariciones, 89 \%), "Terrorismo" (28 apariciones, 80 \%), "Economía" (27 apariciones, 77 \%) y "España" (27 apariciones, 77 \%). Junto a esa casi veintena de temas constantes, coexisten otros que se abordan de manera más puntual, en función de la coyuntura y de si son o no noticiables. En sentido contrario, también es posible encontrar "temas de importancia para el conjunto de la Nación (desempleo) o asuntos socialmente sensibles (maltrato a la mujer) que, incorporados ya a la serie, se abordan en discursos posteriores, indepen- 
dientemente de que concurra factor de actualidad alguno" (Ventero Velasco, 2010, p. 405).

Asumiendo una perspectiva más fáctica, el propio Ventero Velasco (2010) recalca el vínculo de cada mensaje navideño con las circunstancias concretas en las que ha sido concebido y transmitido. De manera parecida, Medina López (2016, p. 47) incide en su carácter de "balance anual de la marcha de España", al que poco a poco se irán incorporando las referencias a asuntos internacionales de calado. En relación a esta cuestión, Barredo Ibáñez (2013) distingue 3 ejes argumentativos en los mensajes navideños: temas nacionales, temas internacionales y temas relacionados con la Casa del Rey: "todos ellos introducen sensaciones de actualidad, a pesar de que la vocación de permanencia de la institución enclava los mensajes navideños en orientaciones generales" (Barredo Ibáñez, 2013, p. 125).

Desde un punto de vista evolutivo, Ventero Velasco (2010) apunta que, a pesar de la existencia de una serie de temas constantes - tesis que es respaldada por Medina López (2016) - , el tratamiento de estos ha evolucionado, sobre todo a partir de la consolidación de la democracia y la superación de la intentona golpista de febrero de 1981. Por su parte, el propio Medina López (2016, p. 64) detecta un cambio "de intencionalidad y finalidad a lo largo de las décadas". Así, mientras en los primeros mensajes se apreciaba un deseo de consolidar la democracia, las décadas de los 80 y 90 se consagrarían mayoritariamente al afianzamiento de la Corona, el marco jurídico y el régimen de libertades existentes, todo ello sin descuidar las continuas apelaciones a la unidad de España o una vertiente más social. En opinión de este último autor, a partir de 2000 se produce un cambio de rumbo en los mensajes navideños, que paulatinamente se van tornando más permeables a los problemas de la población. Fruto de esa mayor sensibilidad es la aparición de referencias a asuntos novedosos de la agenda mediática - que también pasarían a engrosar las preocupaciones de los españoles recogidas por el CIS-, como la importancia de la investigación o la violencia de género:

Con estas referencias [en relación a la incorporación de aspectos sociales, culturales y educativos a los mensajes navideños] el rey se hace eco de los problemas de la sociedad española, con la que intenta conectar al aludir a cuestiones que preocupan y condicionan a la misma. Se trata, una vez más, de incluir en sus palabras - a manera de polifonía textual - los argumentos dados por otros actores de la vida pública y social del país y que están constantemente en el discurso mediático (Medina López, 2016, p. 55).

\section{METODOLOGÍA}

Como ya se ha adelantado, la técnica empleada en el presente artículo está basada en el análisis de contenido, término que hoy en día (Mateo Pérez et al., 
Los mensajes navideños de la monarquía Española en el siglo XXI:

¿Un reflejo de los principales problemas del país?

2004) suele reservarse para lo que tradicionalmente se conocía como análisis cuantitativo. En cualquier caso, vale la pena matizar (Berelson, 1952, en Alonso, Volkens y Gómez, 2012, p. 15) que todo análisis de contenido contiene aspectos cualitativos "inherentes al proceso de pasar palabras a números".

El punto de partida metodológico de la investigación aquí desarrollada ha sido la pregunta sobre los 3 principales problemas que existen actualmente en España, cuestión que el CIS implementó en sus barómetros mensuales en una forma prácticamente similar a la actual en 1985. El hecho de que esta constituya una de las preguntas fijas en los barómetros desde entonces ha permitido la construcción de un indicador denominado "Percepción de los principales problemas de España", que se encuentra disponible en la página web del citado organismo. Dicho indicador arranca, efectivamente, en mayo de 1985, aunque solo a partir de enero de 2001 se ofrecen series anuales completas, lo que, unido a la carga simbólica que supone el cambio de siglo y milenio, ha determinado que el alcance temporal de este estudio abarque, ambos inclusive, desde el citado 2001 hasta 2015, año en que el monarca pronunció el que es su último mensaje navideño en el momento de escribir estas líneas

Partiendo de la citada serie, se ha extraído un listado con los 52 problemas más importantes de España - excluyendo las opciones "Otras respuestas", "Ninguno" "N.S." y "N.C." - recogidos por el CIS a finales de septiembre de 2016. Esos 52 problemas han sido introducidos en el programa Atlas.ti como códigos, elementos cuya función consiste en "capturar algún significado en los datos y buscar ocurrencias (...) que no podrían ser encontrados automáticamente (...). De esta manera es posible la comparación de los contextos en los cuales aparece el concepto al que se refiere el código" (Penalva et al., 2015, p. 130).

En paralelo a esa operación de codificación anterior al análisis, se han introducido en el programa Atlas.ti los 15 mensajes navideños correspondientes al periodo analizado, convenientemente transcritos, sometidos a un somero proceso de corrección de errores ortográficos y gramaticales, y adaptados al formato de texto enriquecido (o RTF, por sus siglas en inglés). Dichos mensajes han constituido los documentos primarios, esto es, los datos textuales que han servido de base para el análisis. Todos ellos han sido obtenidos previamente en la página web de la Casa Real, excepto el mensaje de 2005, que, al presentar en esta una estructura disímil - carente de párrafos-, ha sido tomado de otra fuente, en este caso la edición digital del diario El Mundo. De esta manera, ha quedado conformada la Unidad Hermenéutica, a la que se ha denominado Mensajes navideños siglo XXI, y mediante la cual se ha hecho efectiva la labor de codificación textual. Una vez llevada a cabo esta, se ha recurrido, para el análisis estadístico de los datos, al programa SPSS y, para su presentación, a las hojas de cálculo de la aplicación Microsoft Excel.

A la hora de escoger una unidad de análisis - una de las decisiones metodológicas críticas en el análisis de contenido (Krippendorff, 1990) - se ha optado 
por el párrafo, por su condición operativa de unidad intermedia entre la oración y el texto, su coherencia interna y su relación con el concepto lingüístico de tópico del discurso (Martínez Caro, 2014). Es importante remarcar, en este punto, que la estructuración por párrafos de un texto tiene a veces mucho de subjetivo o de arbitrario (Hannay y Mackenzie, 2009, en Martínez Caro, 2014). Tal podría ser el caso, al menos esporádicamente, de la transcripción de los mensajes navideños ofrecida en la web de la Casa Real - que, como se ha dicho, ha constituido la fuente de los documentos primarios -, si bien, como demuestra el Gráfico 1, el número de palabras por párrafo en ellos se mantiene más o menos constante a lo largo de toda la serie, con una media de 42,47 y una desviación típica de 8,5.

Gráfico 1. Número de palabras por párrafo en los mensajes navideños del rey

(2001-2015)

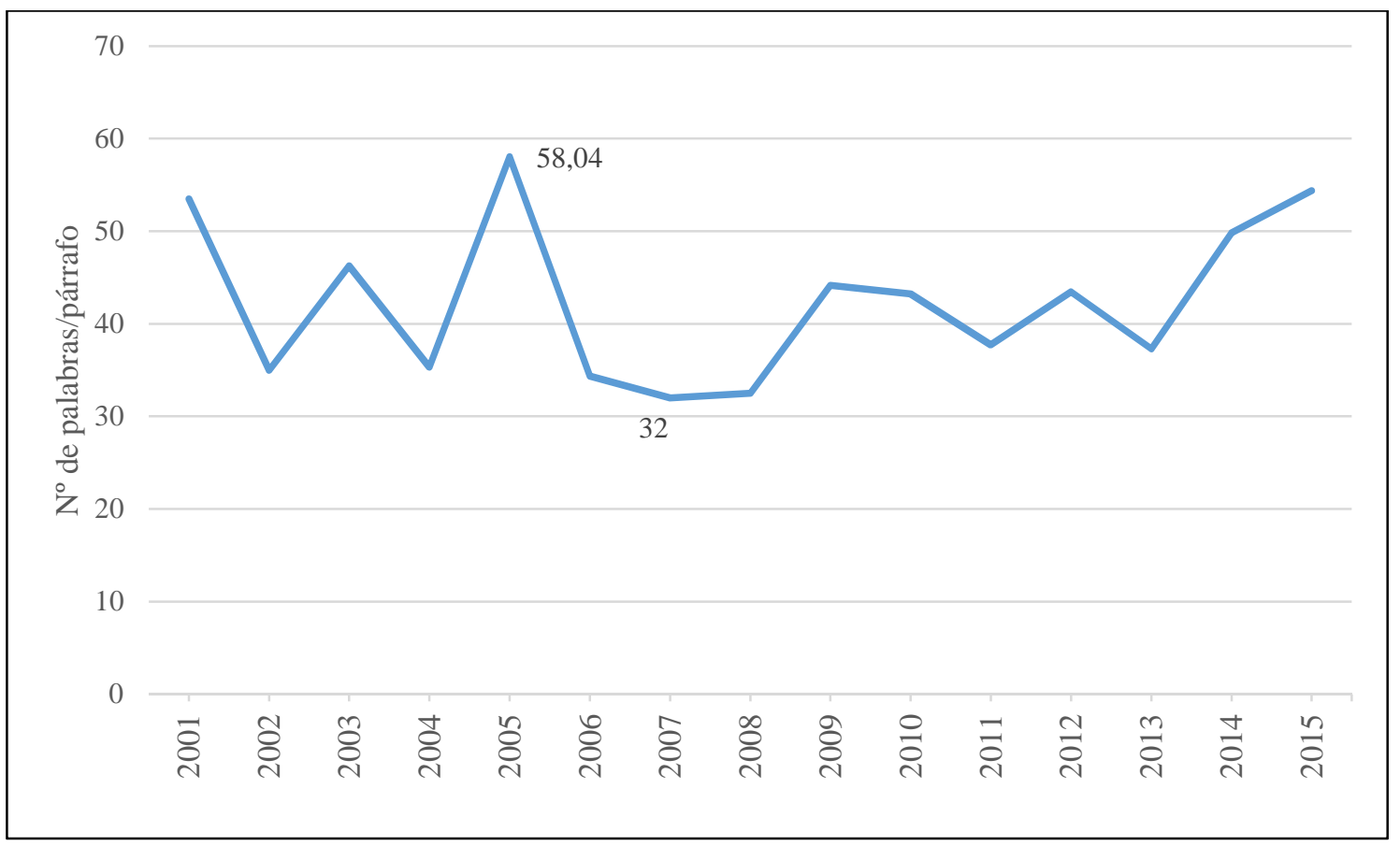

Fuente: Elaboración propia a partir de los mensajes navideños del rey (varios años)

Una vez creada la Unidad Hermenéutica, y determinada la unidad de análisis, se ha creado ad hoc una unidad de medida: la alusión. A los efectos de esta investigación, debe entenderse por tal toda referencia contenida en un párrafo de un mensaje navideño, explícita o implícita, a uno de los principales problemas de España, de forma que, efectivamente, las palabras del monarca dejen traslucir la existencia de un conflicto, una preocupación o una dificultad, ya sean estos manifiestos o latentes, reales o potenciales. En consecuencia, no se trata de que se haga referencia a un tema, sino de que dicha referencia refleje o deje entrever un enfoque problemático. Por ejemplo, en los mensajes navideños son constantes las menciones al papel de la Corona. Sin embargo, y a pesar de aparecer, precisamente, "La Corona" como uno de los principales problemas de 
Los mensajes navideños de la monarquía Española en el siglo XXI:

¿Un reflejo de los principales problemas del país?

España en los barómetros del CIS - cierto es que no entre los más importantes-, en dichas menciones no existe atisbo ninguno de problematicidad ni de cuestionamiento de la institución, por lo que no han sido catalogadas como alusiones. En cambio, en el breve párrafo "También demandan [los españoles] viviendas asequibles, un entorno natural protegido y un creciente esfuerzo investigador" (Mensaje de Navidad de 2004, párrafo 21) se han encontrado 3 alusiones a los principales problemas de España, con los códigos "La vivienda", "Los problemas medioambientales" y "Falta de inversión en industrias e I+D", respectivamente.

Resulta innegable que la definición de la unidad de medida - la alusión - es lo suficientemente flexible y abierta como para dar lugar a algunas ambigüedades. Sin embargo, el poder connotativo y sugeridor del lenguaje ha obligado a recoger posibles lecturas entre líneas o no literales del contenido de los mensajes navideños, máxime teniendo en cuenta la multitud de elementos implícitos, sobreentendidos o contextuales presente en los mensajes navideños (Medina López, 2016; Ventero Velasco, 2010). En la práctica, esa flexibilidad y apertura conceptuales, unidas al uso de anfibologías y al tono deliberadamente impreciso empleado por el monarca, ha provocado dudas en la codificación de algunos pasajes. Por eso, de cara a reforzar la fiabilidad de este y otros estudios similares, sería conveniente recurrir a varios observadores, previa redacción de un manual de codificación. Dado que es posible que, incluso con el uso de dicho instrumento, se filtraran en la labor de estos distintos sesgos, Alonso et al. (2012) recomiendan medir la fiabilidad entre codificadores mediante la alpha de Krippendorff, aunque también contemplan el método de Holsti, la kappa de Cohen o el acuerdo porcentual.

\section{RESULTADOS Y DISCUSIÓN}

\subsection{Grado de presencia absoluta y relativa de los principales problemas de España en los mensajes navideños}

\subsubsection{Grado de presencia absoluta}

Una de las primeras cuestiones a dilucidar en la lógica del estudio atañe al número de ocasiones en que se alude a los principales problemas de España en los mensajes navideños. Dicha cuestión queda reflejada en el Gráfico 2. El Gráfico 2 pone de manifiesto importantes oscilaciones en el número de alusiones a los principales problemas de España, con dientes de sierra notables en prácticamente todos los periodos - aunque de manera más clara en los quinquenios 2001-2005 y 2009-2013 - y valores que van desde las 9 alusiones de 2001 hasta las 47 de 2008, con una media de 29 alusiones por mensaje navideño. Aunque la dinámica del número de alusiones es ascendente - lo que podría avalar en parte la tesis de Medina López (2016), en el sentido de que, desde el cambio de si- 
glo, existe una mayor permeabilidad hacia los problemas de España en los mensajes navideños - , la forma del gráfico dibuja más bien una campana, bien es verdad que más abierta en su parte derecha - lo que, en términos de distribución, vendría a ser una curva de asimetría negativa-. De ello se deduce que el número de alusiones alcanza un periodo-meseta, que se inicia en los años centrales del periodo analizado - los coincidentes con el estallido de la crisis económica - y se prolonga hasta 2014, para luego descender lentamente, si bien quedando por encima de los primeros compases del siglo.

Gráfico 2. Número de alusiones a los principales problemas de España en los mensajes navideños del rey (2001-2015)

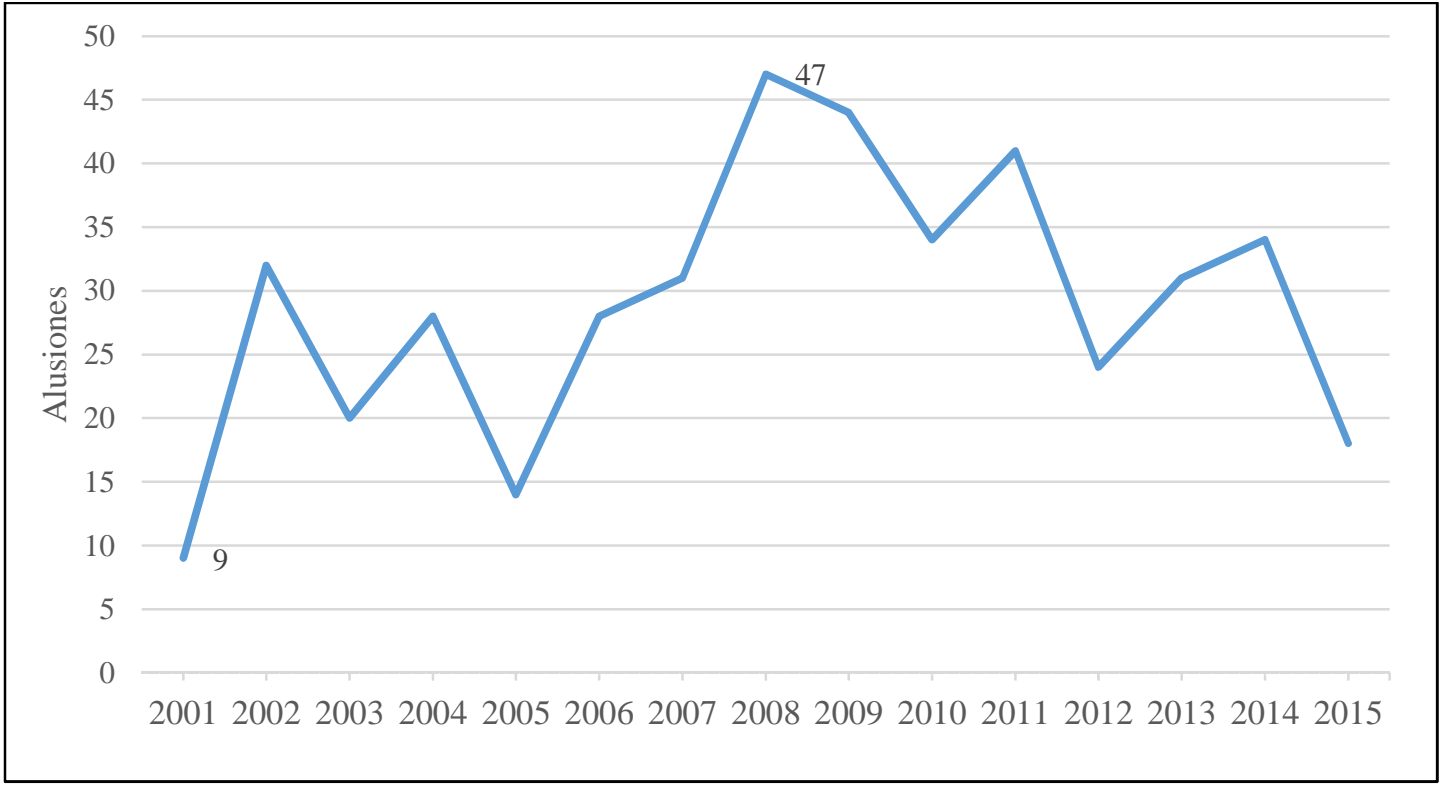

Fuente: Elaboración propia a partir de los mensajes navideños del rey (varios años)

\subsubsection{Grado de presencia relativa}

En cualquier caso, la información bruta ofrecida en el Gráfico 2 debe contextualizarse en sus respectivos mensajes navideños, pues no es lo mismo un número determinado de alusiones en un texto extenso y muy fragmentado (por ejemplo, de 1500 palabras y 45 párrafos) que en uno breve y compacto (por ejemplo, de 900 palabras y 20 párrafos). En consecuencia, conviene, como mínimo, poner en relación el número de alusiones de cada mensaje navideño con su extensión en palabras o en número de párrafos. A ello está consagrado el Grafico 3, de doble eje. 
Gráfico 3. Número de alusiones por cada 1000 palabras y por párrafo en los mensajes navideños del rey (2001-2015)

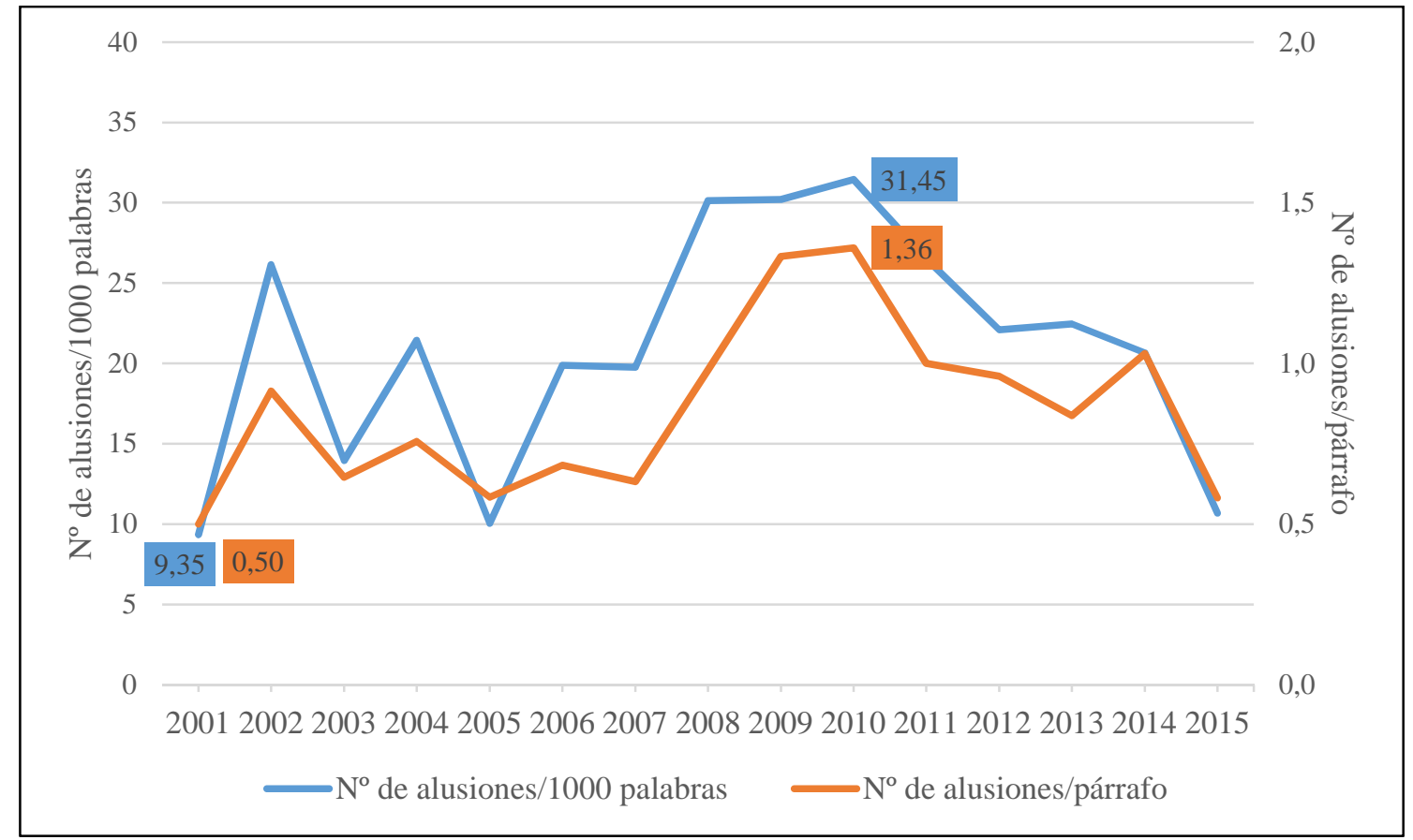

Fuente: Elaboración propia a partir de los mensajes navideños del rey (varios años)

Varias cuestiones pueden destacarse en el Gráfico 3. En primer lugar, el relativo paralelismo entre las ratios de alusiones por cada 1000 palabras y alusiones por párrafo, lo que parece avalar la fiabilidad de la utilización del párrafo como unidad de análisis en este estudio. En segundo lugar, se confirma la dinámica ascendente del número de alusiones y la forma más bien acampanada de ambas variables. Por último, es posible observar algunos cambios respecto al Gráfico 2, pues mientras en este el número máximo de alusiones brutas corresponde a 2008, en el Gráfico 3 las ratios más elevadas se sitúan en 2010. Ello se explica por el hecho de que el mensaje de Navidad de 2008 es el segundo más largo, tanto en número de palabras como en párrafos, de toda la serie analizada, lo que le hace descender posiciones al estar las alusiones más distribuidas. Al margen de esas observaciones, cabe señalar que el número de alusiones por párrafo va desde 0,5 en 2001 hasta 1,36 en 2010, con una media de 0,85, mientras que el número de alusiones por cada 1000 palabras va desde las 9,35 de 2001 hasta las 31,45 de 2010, con una media de 20,98.

\subsubsection{Distribución de las alusiones en los mensajes navideños}

Conviene tener en cuenta en la presente investigación que unos párrafos pueden no contener ninguna alusión, mientras que otros pueden incluir varias. Por ejemplo, en el mensaje navideño de 2008 se dedican 7 párrafos seguidos a hablar exclusivamente del problema "El terrorismo. ETA", mientras que, en ese 
mismo mensaje, el párrafo 26 , de apenas 37 palabras, alude a 4 de los principales problemas de España. Por esa razón, se complementa la información de los gráficos anteriores analizando qué porcentaje de alusiones contienen los párrafos en cada mensaje navideño, tarea que se presenta en el Gráfico 4 y la Tabla 1.

Gráfico 4. Porcentaje de párrafos según número de alusiones a los principales problemas de España en los mensajes navideños del rey (2001-2015)

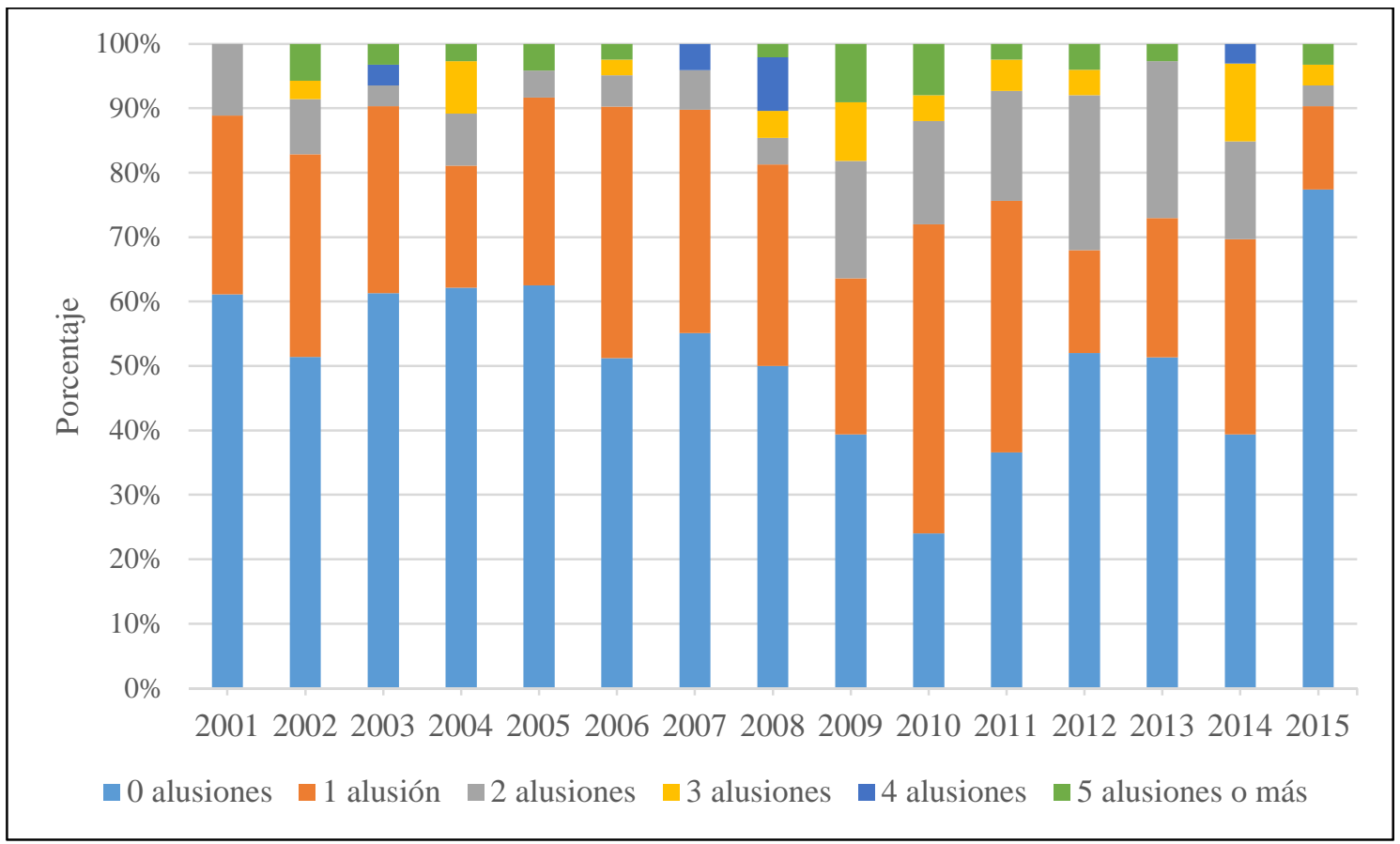

Fuente: Elaboración propia a partir de los mensajes navideños del rey (varios años)

Tabla 1. Porcentaje de párrafos según número de alusiones a los principales problemas de España en los mensajes navideños del rey (2001-2015)

\begin{tabular}{cc} 
№ de alusiones & \% de párrafos \\
\hline 0 & 51,66 \\
\hline 1 & 28,89 \\
\hline 2 & 11,22 \\
\hline 3 & 3,66 \\
\hline 4 & 1,24 \\
\hline 5 o más & 3,32
\end{tabular}

Fuente: Elaboración propia a partir de los mensajes navideños del rey (varios años)

Del Gráfico 4 y la Tabla 1 es posible inferir, en primer lugar, que los párrafos que aluden a alguno de los principales problemas de España son algo menos de la mitad del total - exactamente un $48,34 \%$ - En cuanto a la distribución de 
Los mensajes navideños de la monarquía Española en el siglo XXI:

¿Un reflejo de los principales problemas del país?

dichos párrafos, parece haber un punto de inflexión al alza, bien es verdad que no muy drástico, en el año 2008, a partir del cual su número se mantiene casi siempre por encima del $50 \%$, hasta 2014 inclusive. Ese periodo, y más en concreto los años 2009, 2010, 2011 y 2014, se presenta, pues, como aquel en el que el monarca de turno se ha mostrado más cercano a los problemas del país. Todavía más específicamente, el año 2010 encabeza este ranking, con alusiones en más del $75 \%$ de sus párrafos. En el polo opuesto, el mensaje navideño de 2015 se revela, de largo, como el que menos alusiones contiene.

\subsection{Comparativa entre los principales problemas de España en los baróme- tros de CIS y en los mensajes navideños}

Como se puede apreciar en la Tabla 2 y el Gráfico 5, entre los 5 primeros puestos por número de alusiones en los mensajes navideños aparecen 4 de los 5 principales problemas de España según los barómetros del CIS. Sin embargo, la posición de los problemas en ambas listas difiere: mientras "El paro" se erige como el principal problema del país para la ciudadanía en los barómetros, en los mensajes navideños queda relegado a un discreto 5. puesto. En estos últimos, el 1. ${ }^{\text {er }}$ lugar corresponde a otro problema de cariz material, aunque de expresión más genérica: "Los problemas de índole económica", que ocupa el 2.. puesto entre los problemas del CIS. Queda así patente, pues, el protagonismo de los aspectos económicos en las preocupaciones de la ciudadanía. En un nivel inmediatamente inferior a esta temática se sitúa "El terrorismo. ETA", aunque, como se analiza en posteriores epígrafes (ver Gráfico 6), se trata de un asunto que llegó a ocupar el 1. ${ }^{\text {er }}$ puesto entre las preocupaciones de la opinión pública en los compases iniciales del siglo. En el listado del CIS siguen "La inmigración" - un asunto que apenas es conceptualizado como problemático en los mensajes navideños, en los que ocupa el 16. ${ }^{\circ}$ lugar - y "Los políticos en general, los partidos políticos y la política". Este aparece en 4 . $^{a}$ posición en número de alusiones en los mensajes navideños, debido no tanto a la corrupción - un fenómeno que aflora con fuerza entre la opinión pública solo a partir de 2012como a los reiterados toques de atención del monarca a los partidos en pro de la pacificación de la vida política y la búsqueda de consensos. 
Tabla 2. Posición y porcentaje (corregido) atribuido a los 5 principales problemas de España según los barómetros del CIS, y posición y porcentaje de los mismos en los mensajes navideños del rey (2001-2015)

\begin{tabular}{lcccc} 
& \multicolumn{2}{c}{ CIS } & \multicolumn{2}{c}{$\begin{array}{c}\text { Mensajes } \\
\text { navideños }\end{array}$} \\
\hline & Posición & $\%$ & Posición & $\%$ \\
\hline El paro & 1 & 27,24 & 5 & 7,13 \\
\hline Los problemas de índole económica & 2 & 11,75 & 1 & 18,16 \\
\hline El terrorismo. ETA & 3 & 10,24 & 3 & 9,20 \\
\hline La inmigración & 4 & 6,58 & 16 & 1,84 \\
\hline $\begin{array}{l}\text { Los políticos en general, los partidos } \\
\text { políticos y la política }\end{array}$ & 5 & 5,90 & 4 & 7,82 \\
\hline
\end{tabular}

Fuente: Elaboración propia a partir de los barómetros del CIS y de los mensajes navideños del rey (varios años)

Más allá del puesto que ocupan los distintos problemas, llama poderosamente la atención en el Gráfico 5 el distinto dimensionamiento de muchos de ellos tanto en una como en otra variable. Cierto es que, como se ha apuntado, las escasas alusiones al problema de "El paro" en los mensajes navideños pueden verse compensadas en cierta forma por el elevado número de las mismas para "Los problemas de índole económica". Sin embargo, resultan muy notorias otras diferencias que no parecen contrabalanceadas por problemas del mismo cariz. De entre ellas, destacan "Los problemas de índole social", que en los barómetros del CIS ocupan el 12. ${ }^{\circ}$ puesto, con un porcentaje corregido de 1,92, mientras que en los mensajes navideños se encaraman al 2. ${ }^{\circ}$ puesto en número de alusiones, con un $12,18 \%$, arrojando una diferencia porcentual de $+10,26^{2}$.

Ese sobredimensionamiento de algunos problemas en los mensajes navideños con respecto a los barómetros del CIS es también visible en "Los problemas relacionados con la juventud" ( $+4,12$ de diferencia porcentual), "El terrorismo internacional (Al Qaeda, $11 \mathrm{~S}, 11 \mathrm{M}$, etc.)" (+3,29), "Los problemas y situaciones personales" $(+2,92)$ o "Los problemas medioambientales" $(+2,79)$. En el otro extremo, existen problemas de cierta relevancia en los barómetros del CIS que no tienen una correlación adecuada en los mensajes navideños. En esa lista de problemas infradimensionados desde la óptica monárquica se encuentran, además del ya comentado de "El paro" (-20,12 de diferencia porcentual), "La inmigración" (-4,74), “La inseguridad ciudadana" (-4,58 \%) o "La vivienda" $(-3,14)$.

\footnotetext{
${ }^{2}$ En este caso, el signo positivo indica sobredimensionamiento, es decir, un mayor peso porcentual de un problema en los mensajes navideños que en los barómetros del CIS. En sentido contrario, el signo negativo indica infradimensionamiento.
} 
Los mensajes navideños de la monarquía Española en el siglo XXI:

¿Un reflejo de los principales problemas del país?

Gráfico 5. Comparativa porcentual entre los principales problemas de España en los barómetros del CIS 3 y en los mensajes navideños del rey (2001-2015)4

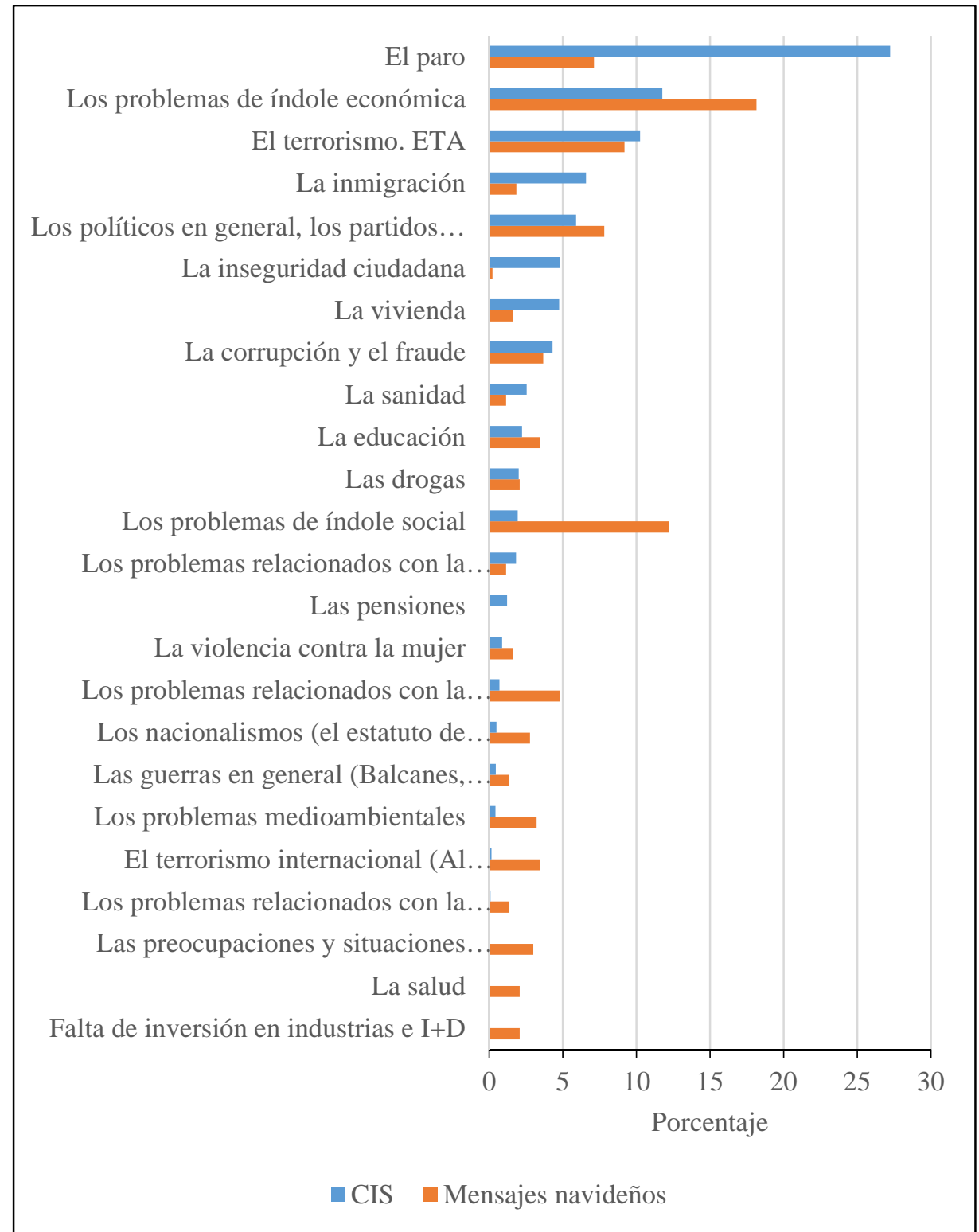

Fuente: Elaboración propia a partir de los barómetros del CIS y los mensajes navideños del rey (varios años)

\footnotetext{
${ }^{3}$ Puesto que los porcentajes de los distintos problemas ofrecidos en los barómetros del CIS suman más de 100, en este gráfico se ha calculado el porcentaje de suma 100 en 3 pasos: primero, hallando el promedio porcentual de cada problema a lo largo de la serie; segundo, sumando todos los promedios; y tercero, aplicando una regla de 3 entre cada promedio y la suma total de los promedios.

${ }^{4}$ Se han eliminado de este gráfico aquellos problemas cuyos porcentajes eran inferiores a 1 en los barómetros del CIS y en el número de alusiones.
} 


\subsection{Evolución de los 5 principales problemas de España en los barómetros de CIS y correspondencia en los mensajes navideños}

Si en el anterior apartado se ofrecía una foto fija de la relación entre las 2 variables estudiadas, en este se presenta una perspectiva diacrónica. Así, el Gráfico 6 analiza la evolución de los 5 problemas más importantes de España según los barómetros del CIS, mientras que el Gráfico 7 se ocupa de la evolución de esos mismos problemas en los mensajes navideños. Llama la atención, en el primero de ellos, la preponderancia del problema "El paro", así como su forma de valle, correlativa a las subidas y bajadas de la tasa de desempleo en España. Además, es de destacar el descenso porcentual del problema "El terrorismo. ETA" desde 2000, apenas interrumpido por un par de repuntes pasajeros en 2004 y 2007. Por último, cabe asimismo poner el foco en el ascenso, en $2008-$ coincidiendo con el estallido de la crisis-, de "Los problema de índole económica", que hasta 2012 atraviesan un periodo-meseta, para disminuir lentamente a partir de entonces.

En lo que respecta al Gráfico 7, sobresale, por un lado, el crecimiento del ítem "Los problemas de índole económica", que desde 2008 - coincidiendo con el estallido de la crisis económica - hasta 2013 ocupa el 1. ${ }^{\text {er }}$ lugar en número de alusiones, para ser relevado en esa escala por "Los políticos en general, los partidos políticos la política", un pico que puede relacionarse con el estallido de varios casos de corrupción y la falta de ejemplaridad de determinados cargos públicos, afectando incluso a la propia Corona. Por otro lado, resulta destacable la escasa presencia en los mensajes navideños del que constituye el 5.. principal problema de España en los barómetros del CIS durante el periodo analizado: "La inmigración". En efecto, el mismo alcanza su cota más alta - un 11,1\%-al principio de dicho periodo, para caer hasta las 0 alusiones entre el periodo 20072014.

Los gráficos 8, 9, 10, 11 y 12, 13, 14 y 15 recogen la evolución de cada uno de esos 5 problemas por separado. A simple vista, en todos ellos es posible apreciar un cierto grado de correlación. 
Los mensajes navideños de la monarquía Española en el siglo XXI: ¿Un reflejo de los principales problemas del país?

Gráfico 6. Evolución de los 5 problemas más importantes de España según los barómetros del CIS (2001-2015)

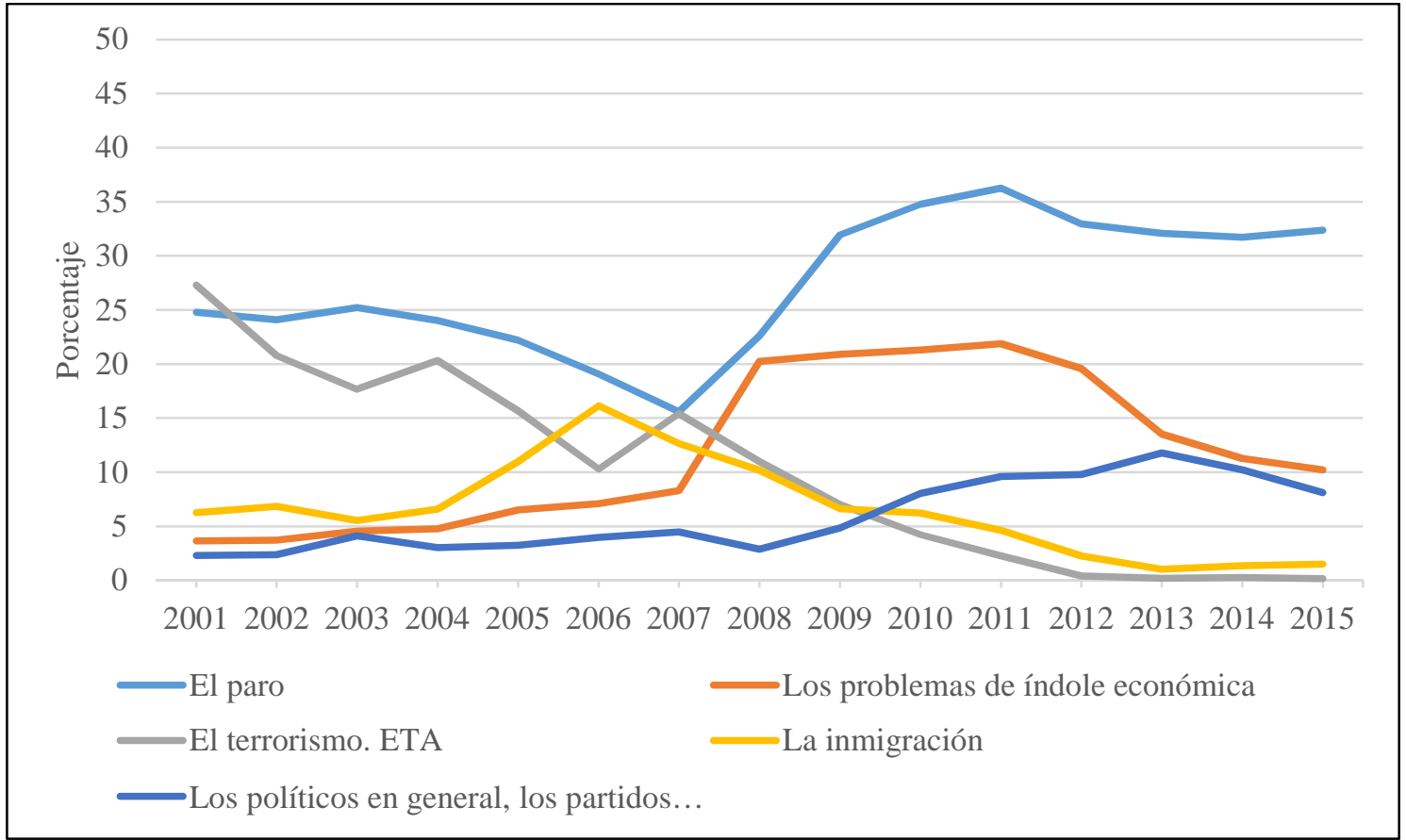

Fuente: Elaboración propia a partir de los barómetros del CIS (varios años)

Gráfico 7. Evolución de los 5 problemas más importantes de España por número de alusiones en los mensajes navideños del rey (2001-2015)

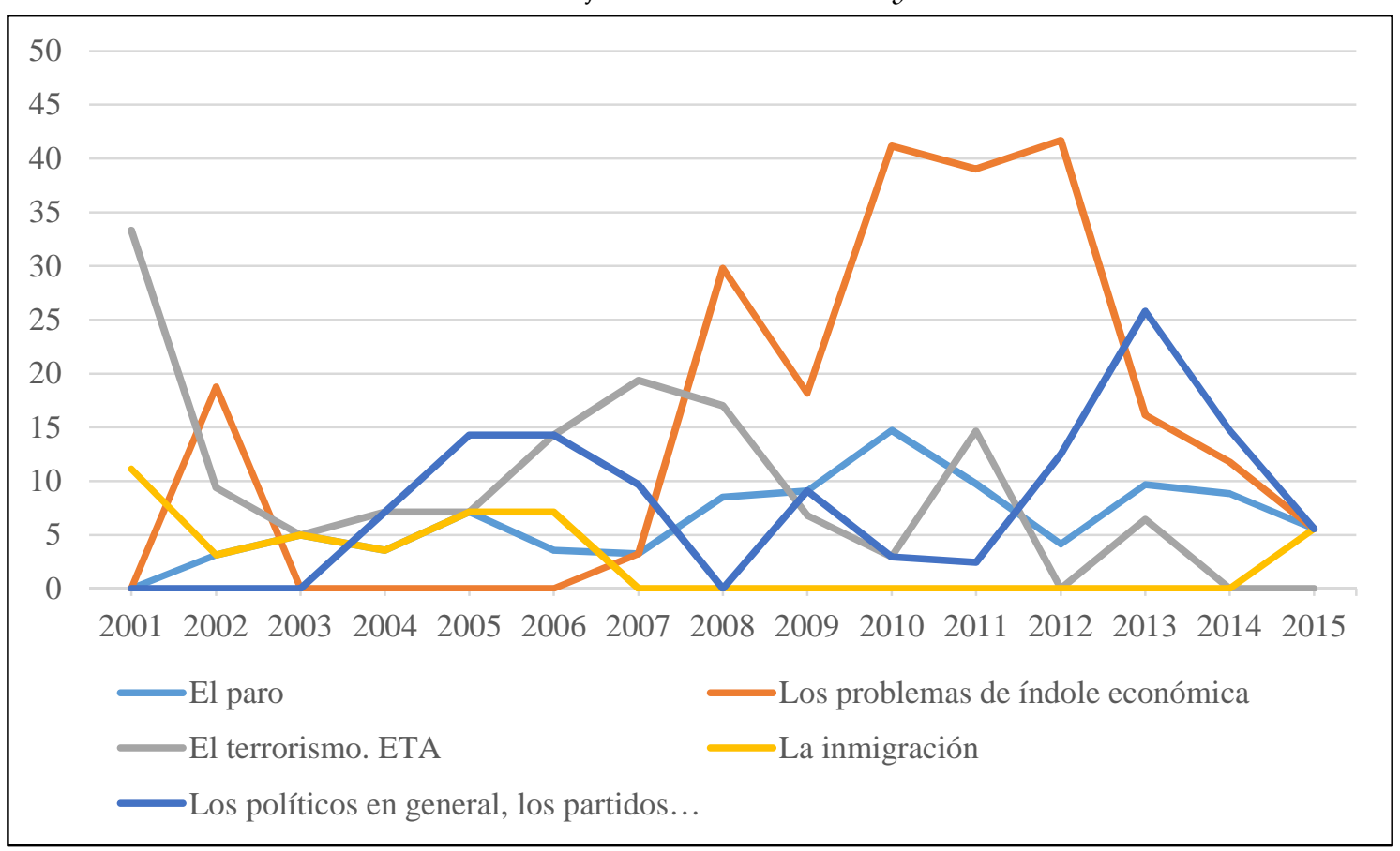

Fuente: Elaboración propia a partir de los mensajes navideños del rey (varios años) 
Gráfico 8. Evolución del problema "El paro" en los barómetros del CIS y los mensajes navideños del rey (2001-2015)

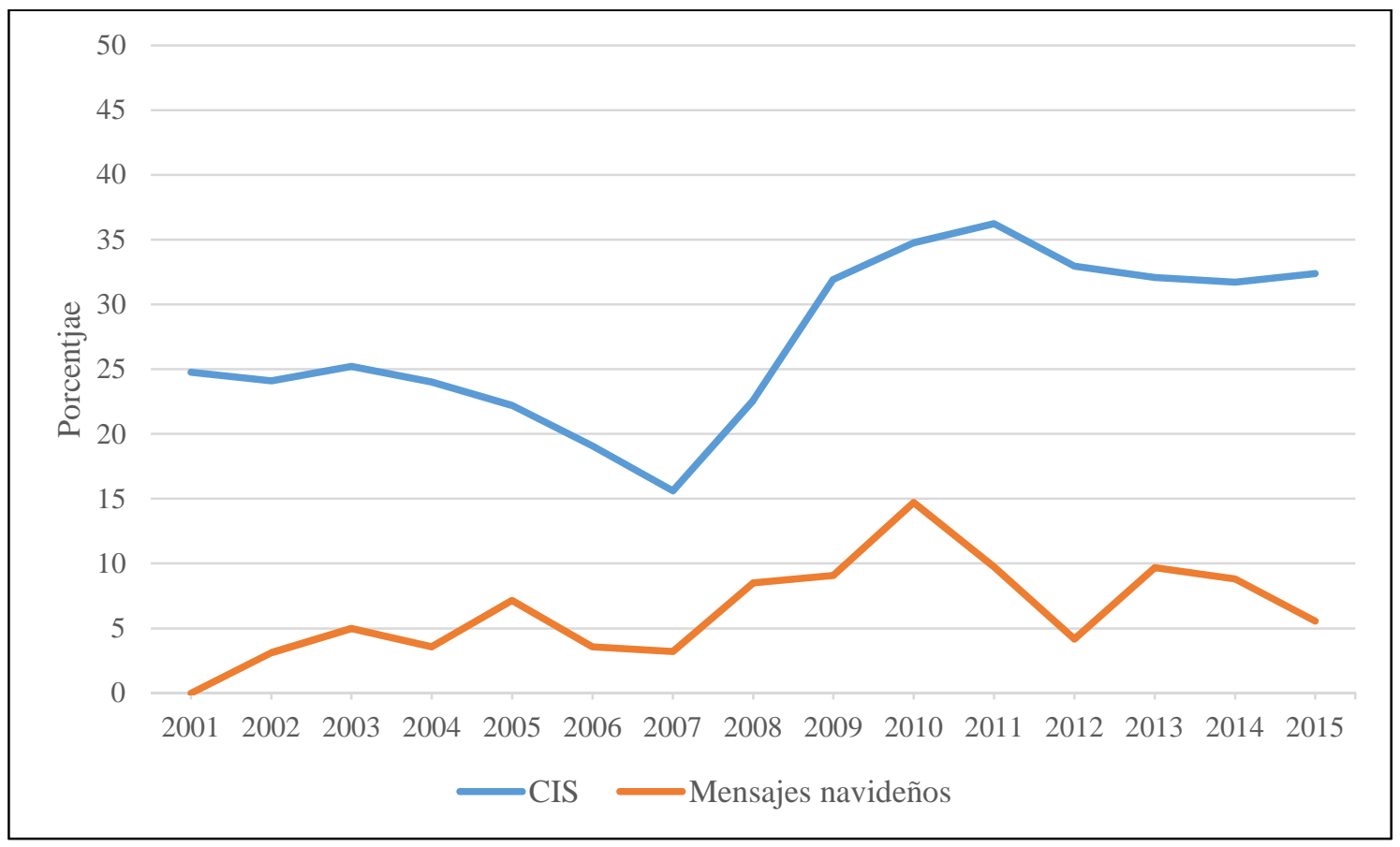

Fuente: Elaboración propia a partir de los barómetros del CIS y de los mensajes navideños del rey (varios años)

Gráfico 9. Evolución del problema "Los problemas de indole económica" en los barómetros del CIS y los mensajes navideños del rey (2001-2015)

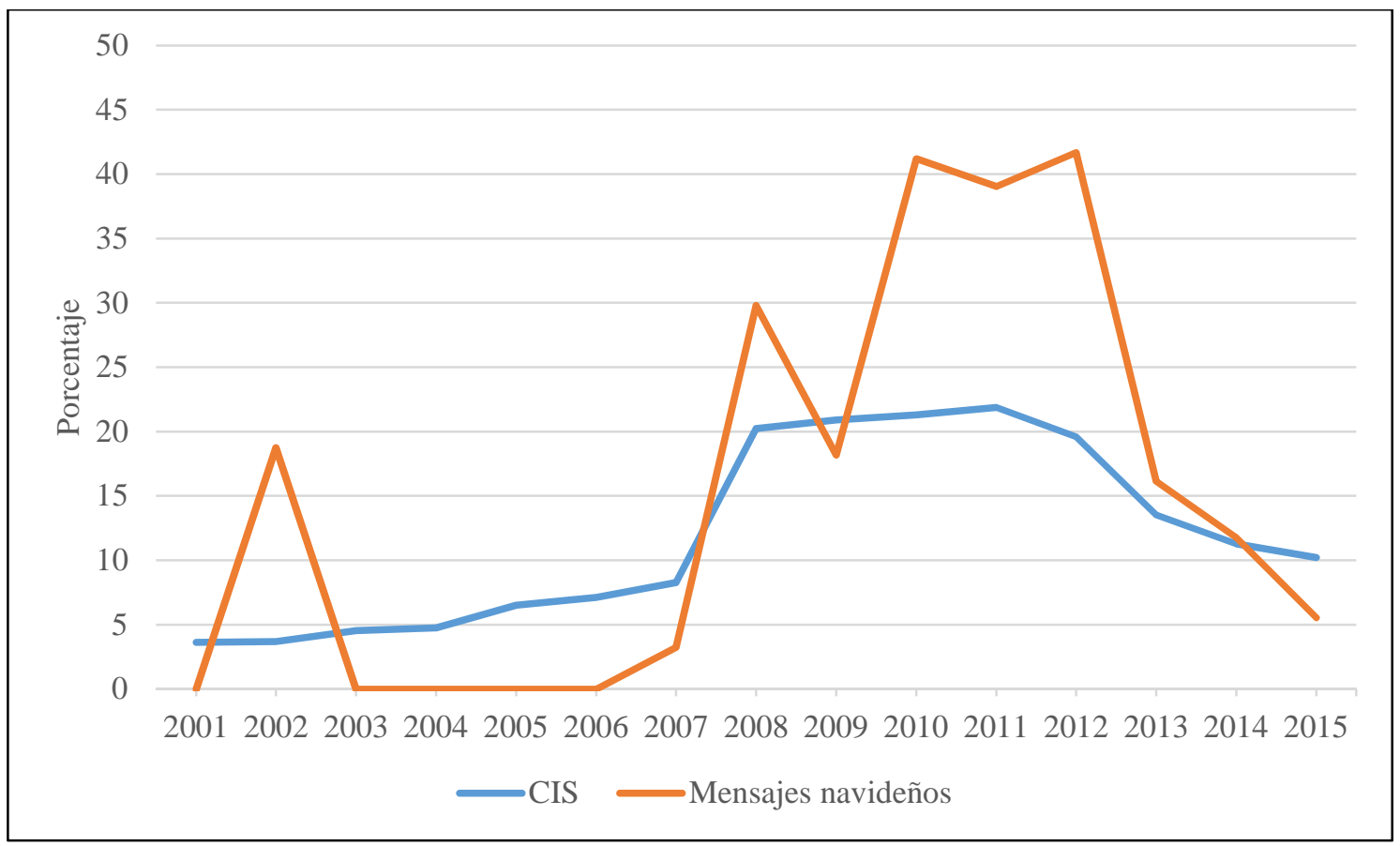

Fuente: Elaboración propia a partir de los barómetros del CIS y de los mensajes navideños del rey (varios años) 
Los mensajes navideños de la monarquía Española en el siglo XXI: ¿Un reflejo de los principales problemas del país?

Gráfico 10. Evolución del problema "El terrorismo. ETA" en los barómetros del CIS y los mensajes navideños del rey (2001-2015)

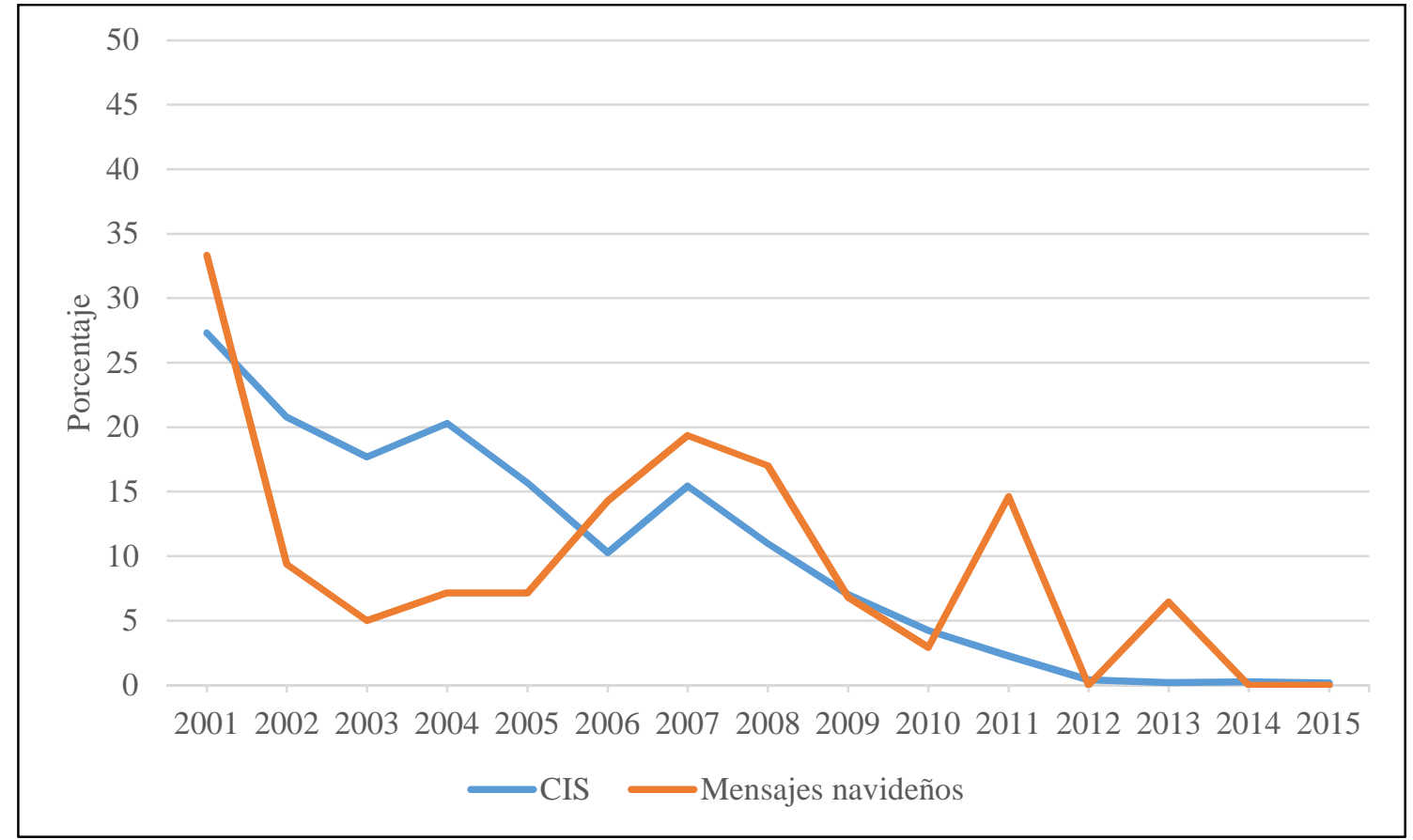

Fuente: Elaboración propia a partir de los barómetros del CIS y de los mensajes navideños del rey (varios años)

Gráfico 11. Evolución del problema "La inmigración" en los barómetros del CIS y los mensajes navideños del rey (2001-2015)

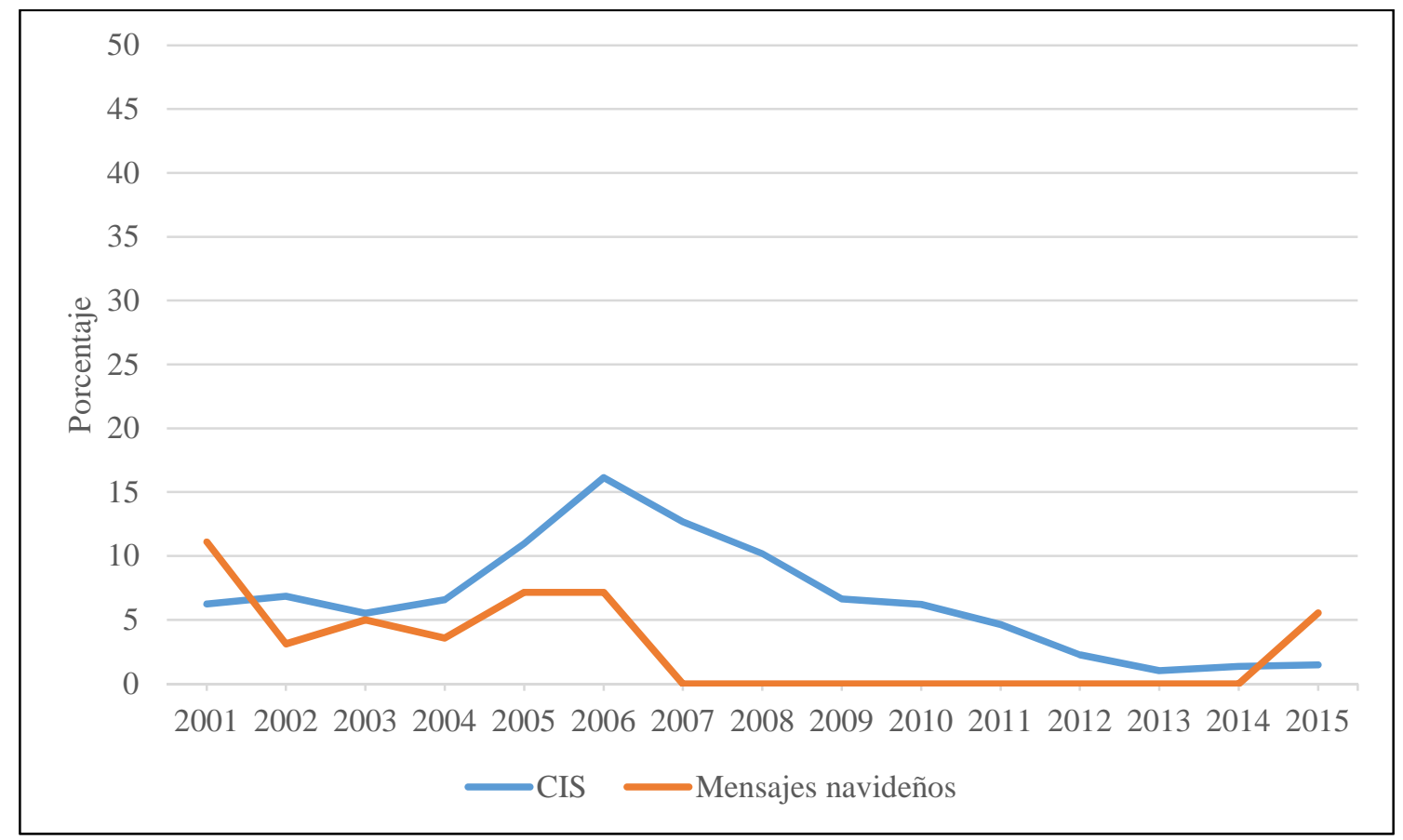

Fuente: Elaboración propia a partir de los barómetros del CIS y de los mensajes navideños del rey (varios años) 
Gráfico 12. Evolución del problema "Los politicos en general, los partidos políticos y la política" en los barómetros del CIS y los mensajes navideños del rey (2001-2015)

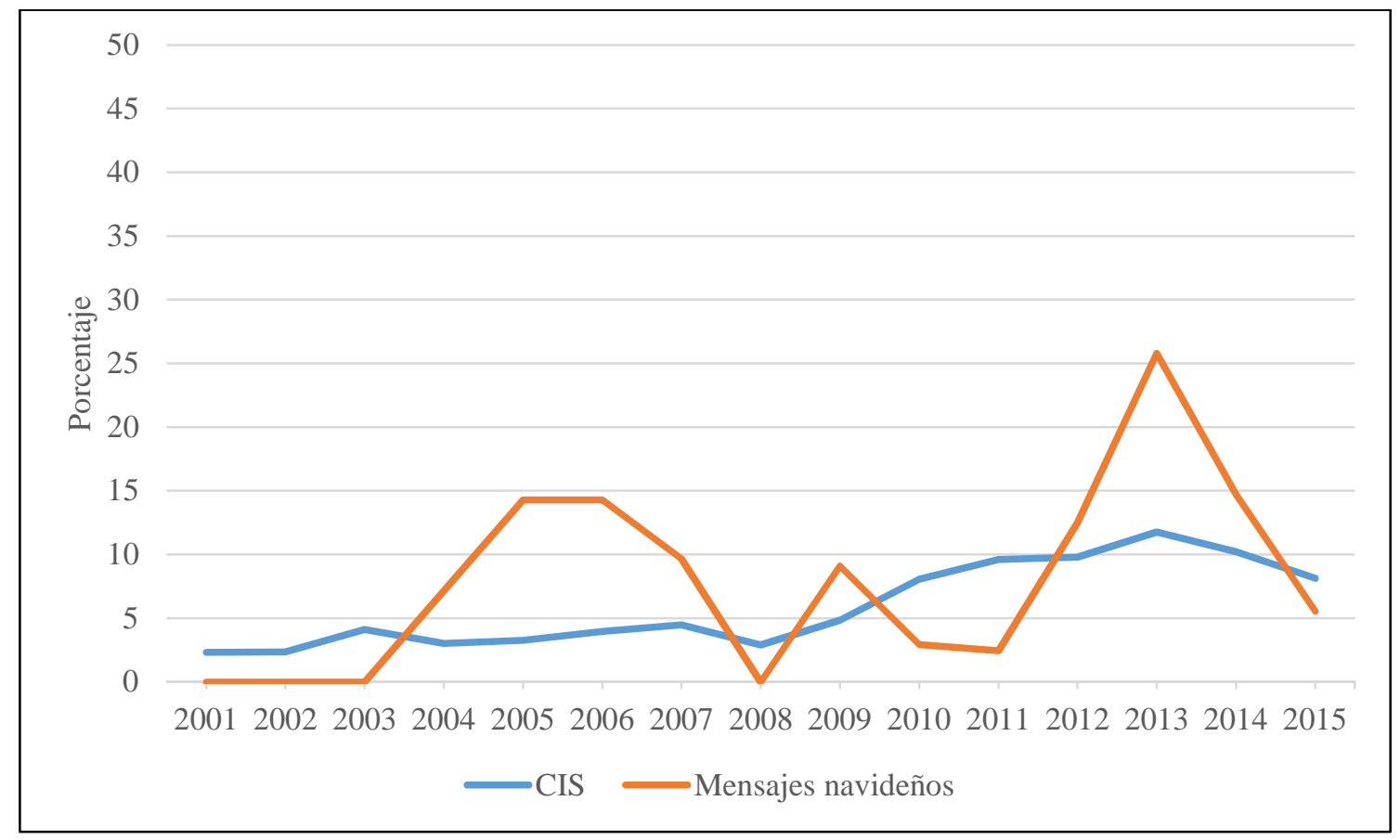

Fuente: Elaboración propia a partir de los barómetros del CIS y de los mensajes navideños del rey (varios años)

La Tabla 3 complementa los gráficos anteriores, explorando, mediante el estadístico $r$ de Pearson, la posible correlación entre la evolución de cada uno de los 5 principales problemas de España según los barómetros del CIS y la forma en que estos son reflejados en los mensajes navideños.

Puede afirmarse, a tenor de la Tabla 3, que existe correlación directa estadísticamente significativa en todos los problemas analizados, excepto en "La inmigración". Siguiendo los criterios de Calvo Gómez (1985), la correlación en "Los problemas de índole económica" puede ser clasificada como muy alta, la de "El paro" y "El terrorismo. ETA" como alta, y la de "Los políticos en general, los partidos políticos y la política" como regular. En otras palabras: los 3 problemas más importantes del país según los barómetros tienen una correspondencia bastante exacta en los mensajes navideños; sin embargo, al descender en la escala de los principales problemas, la correlación entre ambas variables parece ir haciéndose más difusa, o incluso despareciendo. 
Tabla 3. Correlación entre la evolución de los 5 principales problemas de España en los barómetros del CIS y en los mensajes navideños del rey (2001-2015)

\begin{tabular}{lcccc} 
& $\begin{array}{c}\text { Coeficiente } \\
\text { de correlación } \\
\text { (r de Pearson) }\end{array}$ & $\begin{array}{c}\text { Error estándar } \\
\text { de r (95\% de } \\
\text { confianza) }\end{array}$ & p- valor & Correlación \\
\hline El paro & 0,62 & 0,39 & $<0,05$ & Alta \\
\hline $\begin{array}{l}\text { Los problemas de índole } \\
\text { económica }\end{array}$ & 0,86 & 0,25 & $<0,05$ & Muy alta \\
\hline El terrorismo. ETA & 0,63 & 0,38 & $<0,05$ & Alta \\
\hline La inmigración & 0,29 & 0,47 & $>0,05$ & Inexistente \\
\hline $\begin{array}{l}\text { Los políticos en general, } \\
\text { los partidos políticos y la } \\
\text { política }\end{array}$ & 0,52 & 0,42 & $<0,05$ & Regular \\
\hline
\end{tabular}

Fuente: Elaboración propia a partir de los barómetros del CIS y de los mensajes navideños del rey (varios años)

\subsection{Grado de presencia anual o recurrencia de cada uno de los principales problemas de España en los mensajes navideños}

De cara a comprobar las tesis de Ventero Velasco (2010) y Medina López (2016) sobre la existencia de una serie de temas constantes en los mensajes navideños, el Gráfico 13 analiza el porcentaje de recurrencia de los principales problemas de España en los mensajes navideños. A los efectos de esta investigación, se entiende por porcentaje de recurrencia de un problema el tanto por ciento de mensajes navideños en los que existe al menos una alusión a un problema determinado. Así, un porcentaje de recurrencia del $20 \%$ de cierto problema significaría que 3 de los 15 mensajes navideños contienen al menos una alusión al mismo.

Tal como recoge el Gráfico 13, en todos y cada uno de los mensajes navideños analizados aparece al menos una alusión a "Los problemas de índole social", lo que lo convierte en el problema más recurrente en el periodo analizado. Ello no significa que sea el problema con más alusiones totales - tal como se ha expuesto en los 2 epígrafes anteriores, ese lugar le corresponde a "Los problemas de índole económica" - , sino el que tiene una distribución más uniforme. Le siguen, en porcentaje de recurrencia, "Los problemas relacionados con la juventud" (con al menos una alusión en el 93,3 \% de los mensajes navideños analizados), "El paro" (93,3\%), "Las preocupaciones y situaciones personales" (86,7 \%), “El terrorismo. ETA" (80 \%), “La educación” (73,3 \%), “Los políticos en general, los partidos políticos y la política" (73,3\%), “Los problemas de índole económica" (66,7 \%), "Los problemas medioambientales" (60\%) y "La falta de inversión en industrias e I+D" (53,3\%). Por debajo de este último problema, 
otros 23, hasta completar un total de 33 sobre los 52 problemas recogidos por el CIS, reciben al menos alusión, aunque ninguno de ellos sobrepasa un nivel de presencia del $50 \%$, por lo que no pueden ser catalogados como recurrentes.

\section{Gráfico 13. Porcentaje de recurrencia de los principales problemas de España en los} mensajes navideños (2001-2015)

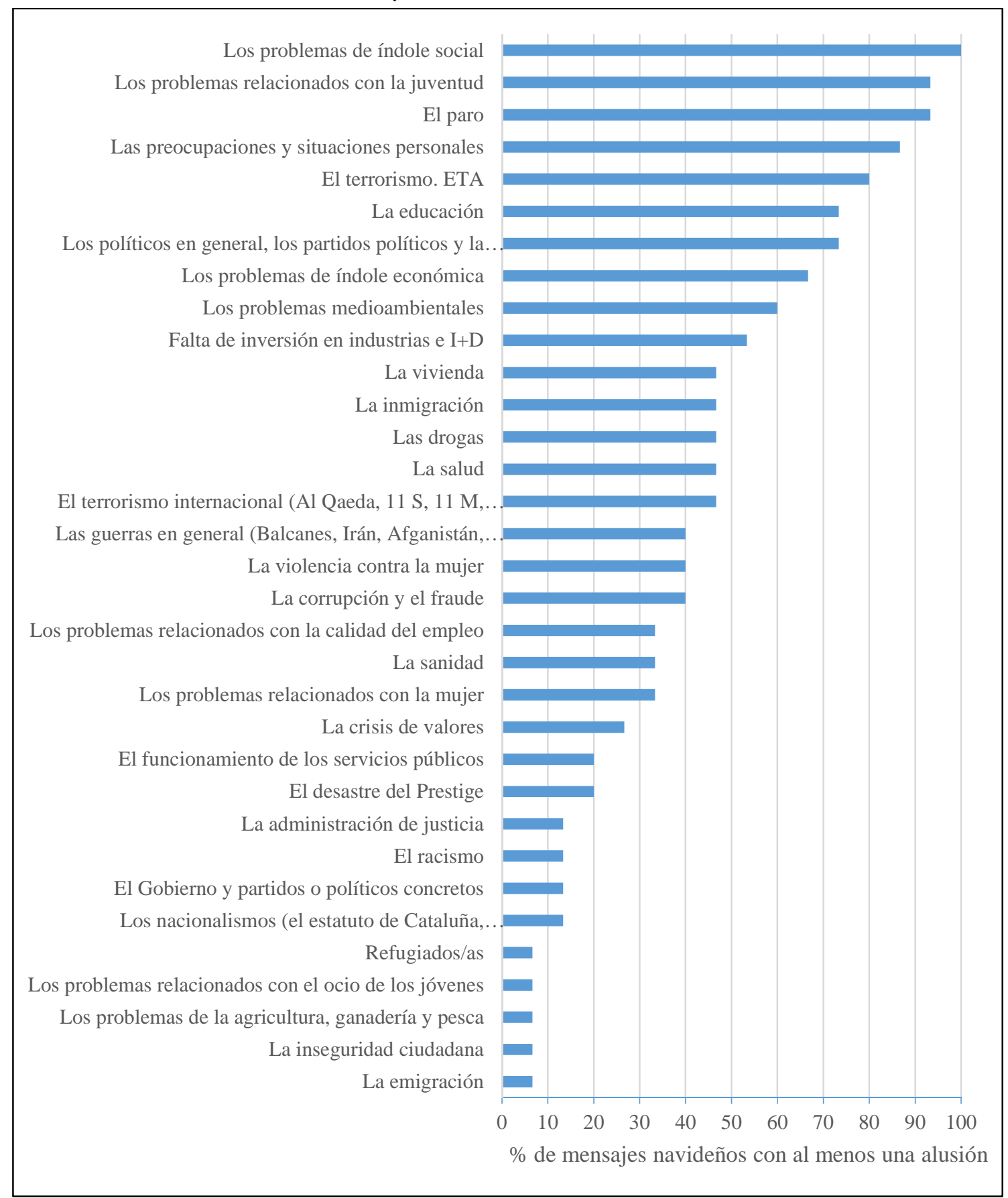

Fuente: Elaboración propia a partir de los mensajes navideños del rey (varios años)

Al margen de lo referido, sorprende en el Gráfico 5 la presencia, en los primeros lugares, de ciertos problemas, como "Los problemas relacionados con la 
Los mensajes navideños de la monarquía Española en el siglo XXI:

¿Un reflejo de los principales problemas del país?

juventud", "Las preocupaciones y situaciones personales" o "Los problemas medioambientales", que no ocupan una posición destacada en el número de problemas con más alusiones totales, y mucho menos entre los principales problemas de España reflejados en los barómetros del CIS, donde se ubican, respec-

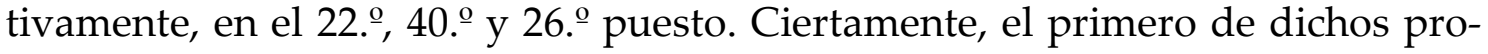
blemas es uno de los catalogados como constantes por Ventero Velasco (2010) con un porcentaje de presencia en la serie histórica del $34 \%-$. Sin embargo, los otros 2 no aparecen siquiera como menciones en la clasificación elaborada por dicho autor, lo que se traduce en una ausencia de correlación entre las dos variables en relación a determinados problemas.

\section{CONCLUSIONES}

El estudio refrenda cuantitativamente, y desde un enfoque inédito, puramente sociológico, muchos de los presupuestos teóricos a los que habían llegado, desde los campos de la comunicación, la lingüística o el análisis de discurso, los escasos análisis diacrónicos efectuados hasta el momento sobre un asunto tan significativo como los mensajes navideños de la monarquía española.

Como punto de partida, se ha demostrado que los párrafos que, en los mensajes navideños, aluden a alguno de los principales problemas de la nación son algo menos de la mitad. Ese rango intermedio puede explicarse por varias razones. En primer lugar, no debe olvidarse el carácter dual de los mensajes navideños, a caballo entre el discurso institucional y su carácter de resumen oficioso de los principales acontecimientos del año (Ventero Velasco, 2010; Medina López, 2016), todo ello sin olvidar su marcado acento político (Gaspar e Ibeas, 2015; Gonzalo, 2001; Herrero Rodríguez de Miñón, 1984; Medina López, 2016; Ventero Velasco, 2010). Ese carácter híbrido -y por tanto, ambiguo o conflictual en ocasiones - se ve reforzado (Medina López, 2016; Prego Vázquez, 1998) por el hecho de que el discurso institucional, debido a sus características intrínsecas, no esté tan ligado a la realidad como otros, verbigracia, el periodístico. En segundo lugar, conviene matizar que no existe ninguna regla, ni escrita ni tácita, que estipule que los mensajes deban ocuparse de los principales problemas de la nación, ni en qué medida. Es más: "el poder de comunicación de la Corona (...) no está expreso en la Constitución (...). No hay (...) ningún precepto que le atribuya aquel poder (...) mediante mensajes y discursos" (Gonzalo, 2001, p. 89). Junto a esta cuestión, deben ser tenidas en cuenta la propia personalidad jurídica del monarca, el ethos y la auctoritas consustanciales a su figura (Belda, 2015; Gaspar e Ibeas, 2015; Medina López, 2016; Ruiz Ruiz, 2001; Ventero Velasco, 2010), así como la función de arbitraje y moderación del funcionamiento regular de las instituciones que le otorga la Constitución Española en su artículo 56.1 (Gil Robles, 2001; Medina López, 2016; Ventero Velasco, 2010). 
Puede afirmarse, a tenor de esta última función, que "los mensajes y discursos del rey exponen el criterio propio y neutral del Jefe del Estado, su opinión no partidaria que sitúa al monarca au dessus de la melé [sic]" (Ventero Velasco, 2010, p. 402). No faltan los autores, que, desde el ámbito de la investigación (Barredo Ibánez, 2013; Ramos, 2012; Ramos Fernández, 2013) o desde el periodístico (Rosa, 2015), han criticado esa excesiva neutralidad, interpretándola como falta de compromiso y empatía de la monarquía con la realidad más acerba del país, patente, precisamente, en los principales problemas de España descritos por los barómetros del CIS. Queda fuera de los objetivos de este análisis juzgar si un rey que reina, pero no gobierna, según el ya clásico apotegma recogido por Ventero Velasco (2010) y Medina López (2016), debe o no descender a la arena del compromiso político-social más allá de lo que lo hace el monarca español. En cualquier caso, vale la pena dejar constancia del intenso debate jurídico, profusamente compilado por Ventero Velasco (2010), sobre si los mensajes navideños deben seguir siendo discrecionales de la persona que ocupa el trono, reforzando así el voluntarismo que preside muchos de los procederes regios, o si, por el contrario, estos deben ser sometidos a una regulación constitucional más estricta, tal como defienden, entre otros, Zarzalejos (2011) y Belda (2015).

Al margen de consideraciones jurídicas y de debates más o menos ideologizados, el estudio ha dejado constancia de que, aunque con altibajos, a partir del año 2008 existe, en los mensajes navideños, una mayor sensibilidad hacia los principales problemas de España. No obstante, esa sensibilidad mengua de manera estrepitosa justo en el último mensaje navideño de la serie, correspondiente a 2015. No es casualidad que el mismo fuera objeto de importantes críticas en la prensa nacional - como las de Alberola (2015), Rosa (2015) o el diario El País (2015) - por su vaguedad y asepsia.

Por otra parte, el hecho de que exista un claro sobredimensionamiento de unos temas y un infradimensionamiento de otros valida la existencia de estrategias de framing y priming en los mensajes navideños detectada por Ventero Velasco (2010), Gaspar e Ibeas (2015) y Medina López (2016). Esas estrategias se articulan, tal como señalan los propios Gaspar e Ibeas (2015) y Medina López (2016), primeramente en torno al sobredimensionamiento de los temas que generan mayor consenso: la necesidad de una mayor igualdad y solidaridad con los desfavorecidos, reflejada en la etiqueta "Los problemas de índole social" en los que, sin embargo, el monarca elude descender a terrenos más concretos como, por ejemplo, los pros y contras de la llamada Ley de dependencia-, los asuntos concernientes a determinados colectivos como "Los problemas relacionados con la juventud", la lógica condena de "El terrorismo internacional (Al Qaeda, 11 S, $11 \mathrm{M}$, etc.)" o las declaraciones en favor de una causa que goza de un alto grado de popularidad y aceptación como "Los problemas medioambientales". En relación a la constante priorización de temas que generen consenso en los mensajes navideños, Gaspar e Ibeas (2016, p. 36; énfasis de los autores) escriben: “Locutor y auditorio pueden discrepar sobre el Modelo de Estado o so- 
Los mensajes navideños de la monarquía Española en el siglo XXI:

¿Un reflejo de los principales problemas del país?

bre el Programa Económico, pero deben estar de acuerdo previamente en la existencia de UN Estado y en la necesidad de UN programa económico".

En lógica contrapartida a lo anterior, se produce un infradimensionamiento de asuntos que podrían indisponer al auditorio contra el rey, al generar incomodidad o desacuerdo. Entre los temas infradimensionados figuran, como se ha expuesto en el epígrafe 4.2., "El paro", "La inmigración”, “La inseguridad ciudadana" o "La vivienda". Aunque las alusiones al primero son frecuentes en los mensajes navideños, el problema aparece englobado a menudo dentro de la etiqueta "Los problemas de índole económica". Por su parte, "La inmigración" apenas es enfocada como un asunto conflictivo en los mensajes navideños. Y en cuanto a "La inseguridad ciudadana" y "La vivienda", las alusiones son escasas y superficiales. Abundando en esa cuestión, resulta significativo que el monarca no aluda ni siquiera una vez en los 15 mensajes navideños analizados a problemas espinosos desde el punto de vista social, como "Los recortes", "Las pensiones", "Los desahucios", "La reforma laboral" o "La ley del aborto". Parece obvio, en consecuencia, que con el tiempo este tipo de cuestiones hayan acabado identificándose, en el imaginario popular, más con la acción del Gobierno o con el resto de poderes del Estado que con la esfera áulica propiamente dicha.

El sobre e infradimensionamiento de ciertos temas tiene también su manifestación en su grado de recurrencia. Así, 3 de los 5 problemas con un mayor porcentaje de recurrencia figuran también entre los 5 más sobredimensionados: "Los problemas de índole social", "Los problemas de índole económica" y "Las preocupaciones y situaciones personales". Junto a ellos, aparecen, entre los más recurrentes, otros 2 tipos de problemas: los que forman parte de "los grandes temas de Estado" (Ventero Velasco, 2010, p. 405), como "El paro" o "El terrorismo. ETA", y los susceptibles de promover un evidente consenso, como "La educación", “Los problemas medioambientales" o "Las drogas".

Puede afirmarse, en definitiva, que los mensajes navideños no permanecen del todo ajenos a los problemas de la nación, e incluso que su sensibilidad hacia los mismos ha ido en aumento, especialmente coincidiendo con el estallido de la crisis económica. Con todo, no debe obviarse la utilización en ellos de determinadas estrategias comunicativas, mediante las que se intenta proyectar una imagen amable de la sociedad española, a menudo bastante alejada de los problemas cotidianos de la ciudadanía. En lo tocante a dichos problemas, el intento de reconstrucción interesada de la realidad por parte del monarca en los mensajes navideños se plasma en una triple línea de actuación: de un lado, cuantitativamente, las alusiones a los problemas no son demasiado numerosas; de otro, selectivamente, se otorga especial protagonismo a aquellos problemas capaces de generar un amplio acuerdo entre la población - "El terrorismo. ETA", "Los problemas de índole social"...-, mientras que los potencialmente conflictivos - "Los recortes", "La ley del aborto", "Las hipotecas"...- son soslayados de manera casi sistemática; por último, cualitativamente, el enfoque de los pro- 
blemas suele ser siempre en positivo, bien quitándoles hierro, bien proponiendo recetas para su superación el día de mañana, es decir, centrando el discurso más en el deber ser futuro que en el ser actual.

A través de ese modus operandi, la Corona no pretende, en última instancia, sino reforzar su papel institucional y el orden establecido (Barredo Ibáñez, 2013; Gaspar e Ibeas, 2015; Medina López, 2016, Ramos, 2012; Ramos Fernández, 2013; Ruiz Ruiz, 2001; Rosa, 2015; Zugasti, 2005). Como siervos de esa función legitimadora y perpetuadora, por un lado, y del rol institucional del jefe del Estado, por otro, los mensajes navideños se ciñen en todo momento (Medina López, 2016) a unas directrices inamovibles. No hay, pues, lugar en ellos para la experimentación o las sorpresas, Y es que, como apuntan Gaspar e Ibeas (2015), en las palabras que el rey dirige a la nación cada Nochebuena se pone en juego algo absolutamente crucial para la monarquía: su propia supervivencia como institución.

\section{Referencias bibliográficas}

Alberola (2015, 26 de diciembre). El Rey llama al diálogo sin aludir a la crisis política ni a la corrupción. elpais.com. Recuperado de

http://politica.elpais.com/politica/2015/12/24/actualidad/1450973348_03490 8.html?rel=mas

Alonso, S., Volkens, A. y Gómez, B. (2012). Análisis de contenido de textos políticos. Un enfoque cuantitativo. Madrid: Centro de Investigaciones Sociológicas. Colección Cuadernos Metodológicos, nº 47.

Ardanaz, N. (2000). Los discursos políticos televisivos durante la Transición española. Filmhistoria online, 1 (3). Recuperado de http://raco.cat/index.php/FilmhistoriaOnline/article/view/243172/325876

Ballenilla y García de Gamarra, M. (2015). Pascua Militar: Las órdenes del Rey a las Fuerzas Armadas. Historia Actual Online, 36 (1), 7-24. Recuperado de http://www.historiaactual.org/Publicaciones/index.php/haol/article/view/1144

Barlovento Comunicación (2015a). Mensaje de S.M. el Rey Felipe VI. Recuperado de

http://www.barloventocomunicacion.es/images/publicaciones/barloventoaudiencias-mensajenavidaddelRey.pdf

Barlovento Comunicación (2015b). Análisis televisivo 2015. Recuperado de http://www.barloventocomunicacion.es/images/publicaciones/analisistelevisivo-2015-Barlovento.pdf

Barredo Ibáñez, D. (2013). El tabú real. La imagen de una monarquía en crisis. Córdoba: Berenice.

Belda, E. (2015). ¿Qué le falta a la monarquía española para estar plenamente racionalizada? (La Monarquía española del siglo XXI). Valladolid: Fundación Aranzadi Lex Nova. 
Los mensajes navideños de la monarquía Española en el siglo XXI:

¿Un reflejo de los principales problemas del país?

Calvo Gómez, F. (1985). Estadística aplicada. Bilbao: Deusto.

CIS (s. f.). Barómetros. Recuperado de http://www.cis.es/cis/opencm/ES/11_barometros/index.jsp

Cruz, M. (2015, 25 de diciembre). Brochazo de Gobierno, pincelada de Rey. elmundo.es. Recuperado de http://www.elmundo.es/espana/2015/12/25/567d2778e2704ebf4b8b456e.ht $\mathrm{ml}$

El Mundo (2005, 24 de diciembre). Mensaje de Navidad del Rey. elmundo.es. Recuperado de http://www.elmundo.es/elmundo/2005/12/24/espana/1135442281.html

El País (2015, 22 de diciembre). Un Rey (muy) discreto. elpais.com. Recuperado de

http://elpais.com/elpais/2015/12/24/opinion/1450959938_407220.html

Gallardo Paúls, B. (2014). Usos políticos del lenguaje: Un discurso paradójico. Barcelona: Anthropos Editorial.

García Fernández, M. D. (2015). Gestión de herramientas 2.0: El caso de la Casa Real. En Túñez López, J. M. y Altamirano Benítez, V. P. (Coords.), Comunicar desde las organizaciones: Tendencias, estrategias y casos (pp. 111-124). La Laguna, Tenerife: Drago.

García Pujol, A. (2016). Comunicación no verbal y mensajes de Navidad: Juan Carlos I (2013) y Felipe VI (2014) (Trabajo de Fin de Grado). Recuperado de https://idus.us.es/xmlui/handle/11441/32674

Gaspar, A. e Ibeas, N. (2015). El discurso institucional en tiempos de crisis: análisis del Mensaje de Navidad de Su Majestad el Rey. Zer, Revista de estudios de comunicación, 20 (38), 31-48. Recuperado de https://dialnet.unirioja.es/servlet/articulo?codigo $=5156054$

Gil Robles, J. M. (2001). El funcionamiento regular de las instituciones del Estado. Las funciones arbitral y moderadora del Rey. En Jornadas de Derecho Parlamentario (7a. 2001. Madrid), VII Jornadas de Derecho Parlamentario: La monarquía parlamentaria: (Título II de la Constitución). Madrid: Publicaciones del Congreso de los Diputados, Dirección de Estudios y Documentación de la Secretaría General.

Gonzalo, M. (2001). Consideraciones sobre los discursos y mensajes del Rey. En Jornadas de Derecho Parlamentario (7ª . 2001. Madrid), VII Jornadas de Derecho Parlamentario: La monarquía parlamentaria: (Título II de la Constitución). Madrid: Publicaciones del Congreso de los Diputados, Dirección de Estudios y Documentación de la Secretaría General.

Gutiérrez, S. (1999, abril). Discurso político y argumentación. Artículo presentado al Tercer Coloquio Latinoamericano de Estudios del Discurso, Santiago de Chile. Recuperado de http://web.uchile.cl/facultades/filosofia/Editorial/libros/discurso_cambio/7 2Gutie.pdf 
Herrero Rodríguez de Miñón, M. (1984). Los Mensajes Regios. En Comares (Ed.), Libro homenaje a Jaime Guasp (pp. 315-325). Granada: Comares.

Humanes, M. L. (2003). La reconstrucción del pasado en las noticias. La representación mediática del 25 aniversario de la muerte de Franco y la coronación de Juan Carlos I. Anàlisi: Quaderns de comunicació i cultura (30), 39-57. Recuperado de https://dialnet.unirioja.es/servlet/articulo?codigo=899247

Kredátusová, M. (2009). Queen's Christmas Speeches 1952-2007: Discourse Analysis (Diploma thesis). Recuperado de https://is.muni.cz/th/152953/pedf_m/diploma_thesis.pdf

Krippendorff, K. (1990). Metodología de análisis de contenido. Teoría y práctica. Barcelona: Paidós.

Martín Jiménez, V. (2008). Mensajes de Navidad para una prensa de transición: repercusión mediática de los discursos de Navidad del rey (1975-1982). Historia Actual Online (17). Recuperado de http://www.historiaactual.org/Publicaciones/index.php/haol/article/viewArticle/265

Martín Jiménez, V. (2010). Las Navidades y el rey: análisis de los mensajes navideños de la corona en Televisión Española durante la transición (19751982). En Enrique Bordería Ortiz, Francesc Andreu Martínez Gallego e Inmaculada Rius Sanchís (Coords.), Política y comunicación en la historia contemporánea (pp. 508-525). Madrid: Fragua.

Martínez Caro, E. (2014). El párrafo como unidad discursiva: consideraciones de forma y contenido relativas a su demarcación y estructuración. Estudios de Lingüística del Español, 35, 197-221. Recuperado de http://infoling.org/elies/35/elies35.1-8.pdf

Martínez-Fornés, A. (2014, 27 de diciembre). ¿Quién se inventó los mensajes de Navidad? abc.es. Recuperado de

http://www.abc.es/casa-del-rey/rey-felipe-vi/20141227/abci-primermensaje-navidad-201412261933.html

Mateo Pérez, M. A., Penalva Verdú, C. y La Parra-Casado, D. (2004). Prensa y ciclos económicos. Encuestas, estadísticas y análisis de contenido. RES. Revista Española de Sociología (4), 219-240. Recuperado de http://hdl.handle.net/10045/1982

Medina López, J. (2016). Discurso institucional e imagen en los mensajes de Navidad del rey de España (1975-2013). Pragmática Sociocultural / Sociocultural Pragmatics. Revista Internacional sobre Lingüística del Español / An International Journal of Spanish Linguistics, 4 (1), 25-73. http://dx.doi.org/10.1515/soprag-2016-0002

Ortega, C., Concejero, P. y de Uña, A. (2014, 13 de marzo). Taller DataMining OpenAnalytics - Los discursos (de Navidad) del Rey 13/03/2014 [Archivo de vídeo]. Recuperado de https://www.youtube.com/watch?v=mz3gR315QFA 
Palacio, M. (2002). Francisco Franco y la televisión. Archivos de la filmoteca: Revista de estudios históricos sobre la imagen, 2 (42-43), 72-95. Recuperado de http://www.uv.es/=imagengc/articulos/Francisco $\% 20$ Franco $\% 20 y \% 201 a \% 2$ Otelevision.pdf

Penalva Verdú, C., Alaminos Chica, A., Francés García, F. J. y Santacreu Fernández, Ó. A. (2015). La investigación cualitativa: técnicas de investigación y análisis con Atlas.ti. Cuenca (Ecuador): PYDLOS Ediciones.

Prego Vázquez, G. (1998). Algunas consideraciones sobre el discurso institucional. Interlingüística (9), 265-268. Recuperado de

https://dialnet.unirioja.es/servlet/articulo?codigo=897083

Ramos, F. (2012). Los escándalos de la Corona española en la prensa digital y el futuro de la monarquía. De la amnesia y el silencio cómplice al tratamiento exhaustivo en los medios. Razón y palabra, 17 (79). Recuperado de

http://www.redalyc.org/pdf/1995/199524411069.pdf

Ramos Fernández, F. (2013). El "tabú" periodístico de la monarquía en España. La crisis real y la crisis coyuntural. Revista Latina de Comunicación Social (68), 217-247. Recuperado de http://www.revistalatinacs.org/068/paper/975_Vigo/09_Ramos.html

Rodríguez García, J. L. (2007). Panfleto contra la monarquía: Sobre la inutilidad de los reyes. Madrid: La Esfera de los libros.

Rosa, I. (24 de diciembre de 2015). El rey nos desea feliz navidad. eldiario.es. Recuperado de http://www.eldiario.es/zonacritica/mensaje_del_rey_20D_6_466213403.ht $\mathrm{ml}$

Ruiz Ruiz, J. J. (2001). Los discursos y mensajes regios como fuente de "auctoritas". En Jornadas de Derecho Parlamentario (7ª . 2001. Madrid), VII Jornadas de Derecho Parlamentario: La monarquía parlamentaria: (Título II de la Constitución). Madrid: Publicaciones del Congreso de los Diputados, Dirección de Estudios y Documentación de la Secretaría General.

Sádaba Garraza, T., Rodriguez Virgili, J. y Bartolomé Castro, M. (2012). Propuesta de sistematización de la teoría del framing para el estudio y praxis de la comunicación política. Observatorio $\left(O B S^{*}\right), 6$ (2), 109-126. Recuperado de

http://obs.obercom.pt/index.php/obs/article/viewFile/540/564

Van Dijk, T. A. (2009). Discurso y poder. Barcelona: Editorial Gedisa.

Ventero Velasco, M. (2010). Los mensajes de Navidad del Rey. Madrid: La Ley.

Zarzalejos, J. A. (2011, 24 de diciembre). Los discursos del Rey y la gubernamentalización de la Corona. elconfidencial.com. Recuperado de http://blogs.elconfidencial.com/espana/notebook/2011-12-24/los-discursosdel-rey-y-la-gubernamentalizacion-de-la-corona_405731/ 
Zugasti, R. (2005). “La legitimidad franquista de la Monarquía de Juan Carlos I: un ejercicio de amnesia periodística durante la transición española. Comunicación y Sociedad, 17(2), 141-168. Recuperado de http://dadun.unav.edu/bitstream/10171/8252/1/20090701091133.pdf

\section{Fuentes de datos:}

Página web de la Casa Real: www.casareal.es Página web del Centro de Investigaciones Sociológicas: www.cis.es

AGUSTÍN GARCÍA-RAMOS es graduado en Sociología por la UNED y la Universidad de Alicante. Posee un Máster Ejecutivo en Community Management y Dirección de Redes Sociales en la Empresa por la UA. Actualmente es colaborador en distintos proyectos públicos de investigación e innovación estratégica.

Recibido: 20/10/2016

Aceptado: 30/11/2016 